\title{
Wake Closure Characteristics and Afterbody Heating On A Mars Sample Return Orbiter
}

\author{
Thomas J. Horvath $^{1}$, F. McNeil Cheatwood ${ }^{2}$, Richard G. Wilmoth ${ }^{1}$ \\ and Stephen J. Alter ${ }^{1}$ \\ ${ }^{1}$ Aerothermodynamics Branch and ${ }^{2}$ Vehicle Analysis Branch, NASA Langley Research Center, Hampton, VA 23681 \\ 757 864-5236; t.j.horvath@larc.nasa.gov
}

\begin{abstract}
Aeroheating wind-tunnel tests were conducted on a 0.028 scale model of an orbiter concept considered for a possible Mars sample return mission. The primary experimental objectives were to characterize hypersonic near wake closure and determine if shear layer impingement would occur on the proposed orbiter afterbody at incidence angles necessary for a Martian aerocapture maneuver. Global heat transfer mappings, surface streamline patterns, and shock shapes were obtained in the NASA Langley 20-Inch Mach 6 Air and CF4 Tunnels for post-normal shock Reynolds numbers (based on forebody diameter) ranging from 1,400 to 415,000, angles of attack ranging from -5 to 10 degrees at 0,3 , and 6 degree sideslip, and normal-shock density ratios of 5 and 12 . Laminar, transitional, and turbulent shear layer impingement on the cylindrical afterbody was inferred from the measurements and resulted in a localized heating maximum that ranged from 40 to 75 percent of the reference forebody stagnation point heating. Comparison of laminar heating prediction to experimental measurement along the orbiter afterbody highlight grid alignment challenges associated with numerical simulation of threedimensional separated wake flows. Predicted values of a continuum breakdown parameter revealed significant regions of non-continuum flow downstream of the flow separation at the MSRO shoulder and in the region of the reattachment shock on the afterbody. The presence of these regions suggest that the Navier-Stokes predictions at the laminar wind-tunnel condition may encounter errors in the numerical calculation of the wake shear layer development and impingement due to non-continuum effects.
\end{abstract}

\section{INTRODUCTION}

As the result of a restructured (Smith, 2000a, 2000b; Pieri, 2000) strategy for the exploration of Mars, it is anticipated that future robotic missions to Mars will continue to gather scientific data and demonstrate technologies required to address the feasibility of eventually establishing a human presence on Mars. The revised exploration architecture calls for a sample return opportunity as early as 2011 (Taverna, 2000). A Mars sample return (MSR) mission would collect terrestrial material from the planet surface and return these samples to Earth for detailed analysis. Although missions designed to return samples from Mars have been considered in the past (Williams, 1990; Meyerson and Cerimele, 1988; Gamble, 1989) all planetary environmental and surface sample data to date has been acquired from remote based measurements obtained from the surface or in orbit of Mars. An MSR round-trip mission could require technologies such as aerocapture, precision landing, remote-controlled surface operations including surface material collection, orbital rendezvous, docking and sample transfer (all at Mars) culminating with a direct entry return at Earth (or shuttle rendezvous).

Prior to the revised Mars exploration architecture, one approach considered for sample return called for a joint US/European MSR mission (Mitcheltree, 1998; Amundsen et al., 2000; Glass and Gnoffo, 2000; Gnoffo, 2001). Key elements of this mission profile are highlighted in Fig. 1. Collected surface samples would be placed into Mars orbit in advance of the arrival of a second vehicle, a French designed (Chanetz, 2001) MSR orbiter (MSRO). Upon planetary approach, the MSRO vehicle would perform an aerocapture maneuver in the Martian atmosphere. With aerocapture, deceleration and orbital insertion is accomplished aerodynamically (in contrast to traditional propulsive techniques) using a blunt aeroshell. After an orbital rendezvous, the material samples would be autonomously transferred to the MSRO and stored in the US-designed (Mitcheltree, 1998) Earth Entry Vehicle (EEV) for the return transit to earth. 
The EEV and the retrieval hardware on the MSRO would reside behind the aeroshell during the aerocapture maneuver prior to its jettison. Proper positioning of this hardware is essential to insure aerodynamic stability of the MSRO during aerocapture, to reduce the chances of biological contamination of the EEV(s), and to avoid thermal damage from localized near wake phenomenon. Although it is generally recognized that convective heating rates to payloads behind aerobrakes are low (Gnoffo, 1999), localized heating maximum can occur if the boundary layer that separates from the shoulder of the aeroshell impinges on the afterbody (Horvath et al., 1996; Horvath et al., 1997; Hollis, 1996; Wells, 1989). The complexity of hypersonic blunt body base flow is shown schematically in Fig. 2.

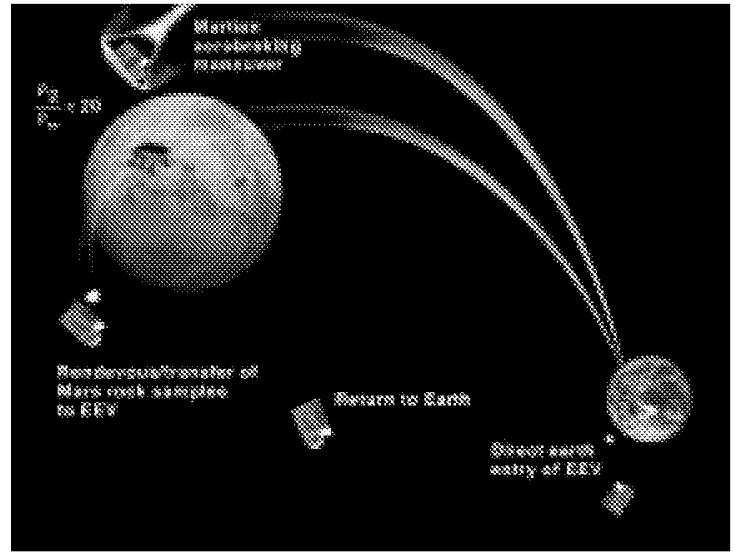

FIGURE 1. Major Elements of a Proposed Mars Sample Return (MSR) Mission.

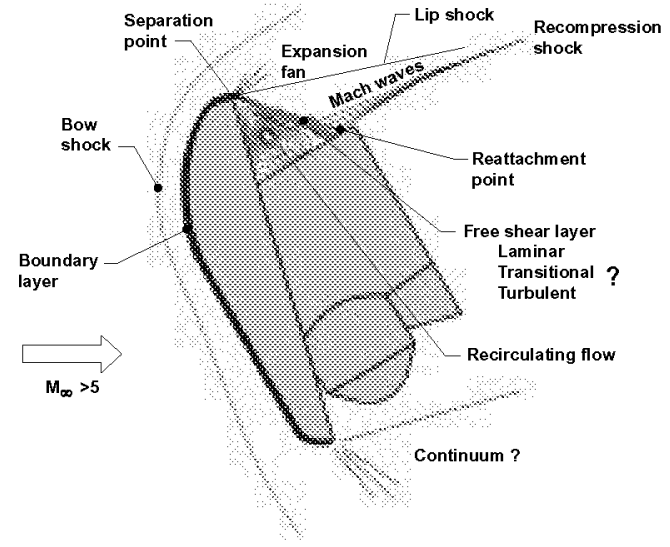

FIGURE 2. Schematic Representation of the Fow Region Behind a Blunt Body in Hypersonic Flow.

The purpose of the present study was to experimentally investigate the near wake closure characteristics of a proposed MSRO vehicle. The primary objective was to experimentally determine if flow impingement occurred on the MSRO afterbody, and if present, determine the location and magnitude of the heating peak for comparison of prediction to measurement. Prediction methods that accurately model the near wake characteristics of blunt bodies are desired to reduce conservative design margins for planetary entry vehicles.

Initial tests in the Langley 20-Inch Mach $6 \mathrm{CF}_{4}$ Tunnel were used to assess laminar MSRO wake closure characteristics because of the facility's ability to provide normal shock density ratios $\left(\rho_{2} / \rho_{\infty}\right)$ of the same magnitude as that incurred in flight. It is anticipated that entry of the MSRO into the atmosphere of Mars (continuum-flow regime) during the aerocapture maneuver will produce values of shock density ratio near 20 (these high values of normal shock density ratio encountered in hypervelocity flight are produced from dissociation of atmospheric gases as they cross through the shock wave into the shock layer and are often referred to as real gas effects). Flight values of normal shock density ratio are significantly larger (3 to 4 times) than those produced in conventional blowdown hypersonic wind tunnels using air or nitrogen as a test gas (Jones, 1974). The NASA Langley 20-Inch Mach $6 \mathrm{CF}_{4}$ Tunnel utilizes a test gas (tetrafluoromethane- $\mathrm{CF}_{4}$ ) with a molecular weight 3 times that of air in order to generate a normal shock density ratio of 12 thereby simulating this particular aspect of a real gas. The simulation is achieved at moderate levels of enthalpy and without dissociation of the test gas. It is well recognized the normal shock density ratio is one of the primary flight simulation parameters that govern the inviscid flow and aerodynamics of blunt bodies at hypersonic speeds (Midden and Miller, 1985). Complimentary tests in a perfect gas Mach 6 air facility were later performed over a larger Reynolds number range to assess the effects of shear layer transition on wake closure and impingement heating.

The MSRO was tested at normal shock density ratios of 12 and 5 (in $\mathrm{CF}_{4}$ and air, respectively) over a range of freestream unit Reynolds number from $3.66 \times 10^{3}$ to $2.44 \times 10^{6}$ per meter (post shock Reynolds number range based on aeroshell diameter of 1,400 to 415,000 ). Angle of attack was varied from -5 deg to 10 deg at zero deg sideslip (limited data at 3 and 6 deg sideslip). Test techniques that were utilized during these tests include thermographic phosphors, which provided global quantitative surface heating images; oil-flow, which provided surface streamline information; and schlieren, which provided shock system details. Emphasis was placed on the afterbody surface heating augmentation due to shear layer impingement. 


\section{EXPERIMENTAL WIND TUNNEL MODELS}

The Outer Mold Lines (OML) of the proposed MSRO vehicle shown in Fig. 3 represents a reference baseline concept for which experimental and computational wake assessment studies can be conducted. The proposed MSRO vehicle consists of a drag brake and a base-mounted cylindrical afterbody $\left(\mathrm{d}_{\mathrm{aft}} / \mathrm{d}_{\mathrm{f}}=0.48\right)$. The base of the drag brake (aeroshell) is concave inwards as shown in Fig. 3. A single EEV for sample storage and a housing structure for the retrieval/transfer hardware are positioned on the afterbody. The drag brake, or aeroshell, is based upon a design detailed by Cheatwood et al. (1986) and originally proposed in support of the Aeroassist Flight Experiment (AFE) - a 60 degree elliptically blunted cone with the base raked at a 73 degree angle. At zero degrees angle of attack, the wind vector is aligned with the minor axis of the ellipsoidal nose.

A photograph of two 0.1016 -m diameter $(0.028$ scale) cast ceramic MSRO models used in the test is shown in Fig. 4. For construction of the fused silica models, a rapid prototyping technique was utilized. Stereolithography (SLA) was used to build a resin aeroshell model with various, detachable SLA afterbodies representing a component buildup of the return orbiter EEV and retrieval/transfer housing structure. The SLA resin aeroshell was then assembled with the desired afterbody; the mated pair served as a pattern to construct molds from which the cast ceramic MSRO models were made. A support sting enters from the rear of the cylindrical afterbody. A magnesia ceramic was used to backfill the cylindrical afterbody, thus providing strength and support to the sting support structure. The aeroshell baseplanes on the MSRO models were constructed both open (concave inwards as sketched in Fig. 3) and closed. A photograph of these two base configurations is shown in Fig. 4.

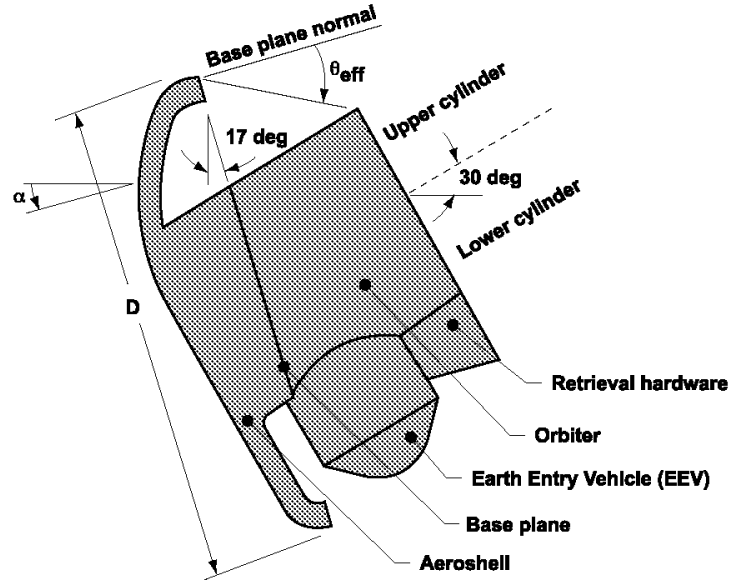

FIGURE 3. Sketch of the Proposed Mars Sample Return Orbiter (MSRO).

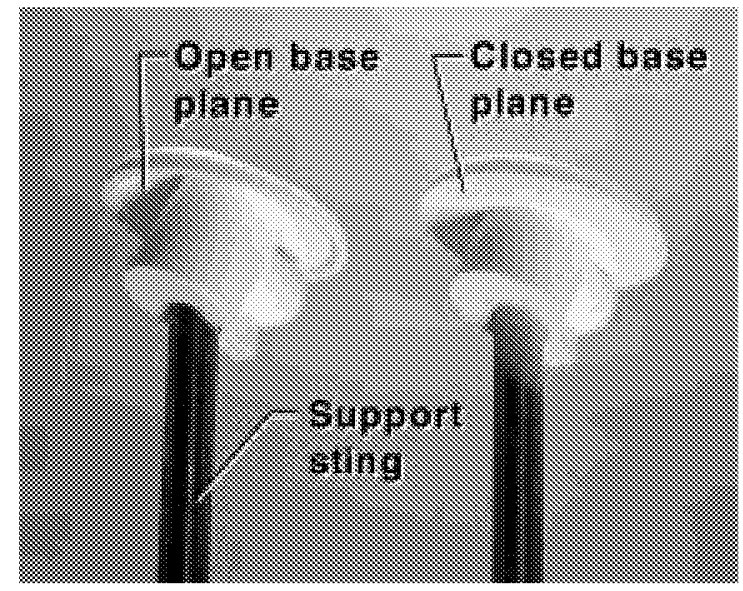

FIGURE 4. 0.028-Scale MSRO Ceramic Heat Transfer Models.

Typically, two casts of each configuration are made; the primary being immediately prepared for testing and the back-up shell held in reserve, in the event of problems with the primary. In order to obtain accurate heat transfer data with the phosphor technique, the models are cast with a material having low thermal diffusivity and well defined, uniform, isotropic thermal properties. The phosphor coatings typically do not require refurbishment between runs in the wind tunnel and have been measured to be approximately $0.0254 \mathrm{~mm}$ thick. Details concerning the ceramic model fabrication technique and phosphor coating can be found in Buck (1993) and Merski (1998a). Fiducial marks were placed on the model surface to assist in determining spatial locations accurately.

\section{FACILITY DESCRIPTIONS}

Tests were conducted in two facilities managed under the Aerothermodynamic Facilities Complex (AFC). This complex presently consists of four hypersonic wind tunnels that represent a large fraction of the nation's conventional aerothermodynamic test capability (Miller, 1990). Collectively, they provide a wide range of Mach number, unit Reynolds number, and normal shock density ratio. This range of hypersonic simulation parameters is due, in part, to the use of two different test gases (air and tetraflouromethane), thereby making the facilities unique national assets. The AFC facilities are relatively small and economical to operate, hence ideally suited for fast- 
paced aerodynamic performance and aeroheating, and transition studies aimed at screening, assessing, optimizing, and bench-marking (when combined with computational fluid dynamics) advanced aerospace vehicle concepts and basic fundamental flow physics research.

\section{0-Inch Mach 6 Air Tunnel}

Heated, dried, and filtered air is used as the test gas. Typical calibrated operating conditions for the tunnel are: stagnation pressures ranging from $2.07 \times 10^{5}$ to $3.45 \times 10^{6} \mathrm{~N} / \mathrm{m}^{2}$; stagnation temperatures from 422 to 556 -degree $\mathrm{K}$; and freestream unit Reynolds numbers from $1.52 \times 10^{5}$ to $2.44 \times 10^{6}$ per meter. A two-dimensional, contoured nozzle is used to provide nominal freestream Mach numbers from 5.8 to 6.1. The test section is 0.521 by 0.508 meters; the nozzle throat is 0.010 by 0.521 -meter. A bottom-mounted model injection system can insert models from a sheltered position to the tunnel centerline in less than 0.5 -sec. For the transient heat transfer tests, the model residence time in the flow was limited to 5 seconds. A detailed description of this facility may be found in Miller (1990).

\section{Mach $6 \mathrm{CF}_{4}$ Tunnel}

Heated, dried, and filtered tetrafluoromethane $\left(\mathrm{CF}_{4}\right)$ is used as the test gas. Typical calibrated operating conditions for the tunnel are: stagnation pressures ranging from $5.86 \times 10^{5}$ to $1.38 \times 10^{7} \mathrm{~N} / \mathrm{m}^{2}$, stagnation temperatures up to 722 -degree $\mathrm{K}$, and freestream unit Reynolds numbers from $3.05 \times 10^{3}$ to $1.25 \times 10^{5}$ per meter. A contoured axisymmetric nozzle is used to provide nominal freestream Mach numbers from 5.9 to 6.2. The nozzle exit diameter is 0.508 meters with the flow exhausting into an open jet test section; the nozzle throat diameter is $0.012-$ meter. A bottom-mounted model injection system can inject models from a sheltered position to the tunnel centerline in less than 0.5 -sec. For the transient heat transfer tests, the model residence time in the flow was limited to 5 seconds. A detailed description of this facility may be found in Midden and Miller (1985).

\section{TEST CONDITIONS AND SETUP}

Nominal reservoir and corresponding free stream flow conditions for the MSRO test series are presented in Tables 1 and 2. The freestream properties were determined from the measured reservoir pressure and temperature and the measured pitot pressure at the test section. Static pressure in the $\mathrm{CF}_{4}$ test section that enclosed the open jet were monitored to assess the potential for contraction of the open-jet test core flow with time during any given run. The ratio of projected model frontal area to core flow cross sectional area for the 0.028 -scale model is approximately 0.15 .

All models were supported by a cylindrical steel rod (sting) which extended downstream from the model base at a 105-degree incidence angle relative to the forebody base plane. This was done to align the sting along a computationally predicted wake axis with the model at zero degree incidence. To determine the sensitivity of the support system on base flow heating, several runs were made with an adapter sleeve placed over the existing sting which increased the sting to forebody diameter ratio $\left(\mathrm{d}_{\mathrm{s}} / \mathrm{d}_{\mathrm{f}}\right)$ from 0.19 to 0.32 . A photograph of the installation in the $\mathrm{CF}_{4}$ tunnel is shown in Fig. 5.

TABLE 1. Nominal Flow Conditions for the NASA LaRC 20-Inch Mach 6 Air Wind Tunnel.

\begin{tabular}{lcccccc}
\hline $\mathbf{R e}_{2, \mathrm{D}}$ & $\mathbf{R e}_{\infty} / \mathbf{m}\left(\mathbf{x} \mathbf{1 0} \mathbf{6}^{6}\right.$ & $\mathbf{M}_{\infty}$ & Test $\mathbf{g a s}$ & $\mathbf{P}_{\mathbf{t}, \mathbf{1}}(\mathbf{k P a})$ & $\mathbf{T}_{\mathbf{t}, \mathbf{1}}\left({ }^{\circ} \mathbf{K}\right)$ & $\rho_{\mathbf{2}} / \boldsymbol{\rho}_{\infty}$ \\
\hline 36,700 & 0.21 & 5.8 & air & 234.4 & 479 & 5.23 \\
65,000 & 0.37 & 5.9 & air & 441.3 & 488 & 5.24 \\
123,000 & 0.71 & 5.9 & air & 896.3 & 501 & 5.25 \\
173,567 & 1.01 & 5.9 & air & 1282.4 & 500 & 5.26 \\
235,967 & 1.38 & 6.0 & air & 1765.1 & 500 & 5.27 \\
325,000 & 1.89 & 6.0 & air & 2564.8 & 517 & 5.27 \\
415,000 & 2.44 & 6.0 & air & 3309.5 & 514 & 5.27 \\
\hline
\end{tabular}


TABLE 2. Nominal Flow Conditions for the NASA LaRC 20-Inch Mach $6 \mathrm{CF}_{4}$ Wind Tunnel.

\begin{tabular}{lcccccc}
\hline $\mathbf{R e}_{2, \mathrm{D}}$ & $\mathbf{R e}_{\infty} / \mathbf{m} \mathbf{( \mathbf { x } 1 \mathbf { 6 } ^ { \mathbf { 6 } } )}$ & $\mathbf{M}_{\infty}$ & Test $\mathbf{g a s}$ & $\mathbf{P}_{\mathbf{t}, \mathbf{1}}(\mathbf{k P a})$ & $\mathbf{T}_{\mathbf{t}, \mathbf{1}}\left({ }^{\circ} \mathbf{K}\right)$ & $\rho_{2} / \rho_{\infty}$ \\
\hline 1,420 & 0.003 & 6.2 & $\mathrm{CF}_{4}$ & 420.6 & 703 & 12.1 \\
2,510 & 0.006 & 6.0 & $\mathrm{CF}_{4}$ & 565.4 & 697 & 11.9 \\
3,946 & 0.009 & 6.0 & $\mathrm{CF}_{4}$ & 813.6 & 688 & 11.9 \\
15,727 & 0.04 & 5.9 & $\mathrm{CF}_{4}$ & 2689 & 672 & 11.7 \\
30,200 & 0.07 & 5.8 & $\mathrm{CF}_{4}$ & 5150.4 & 712 & 11.8 \\
44,000 & 0.11 & 5.9 & $\mathrm{CF}_{4}$ & 7398.1 & 693 & 11.7 \\
52,442 & 0.12 & 5.9 & $\mathrm{CF}_{4}$ & 9059.7 & 709 & 11.8 \\
\hline
\end{tabular}

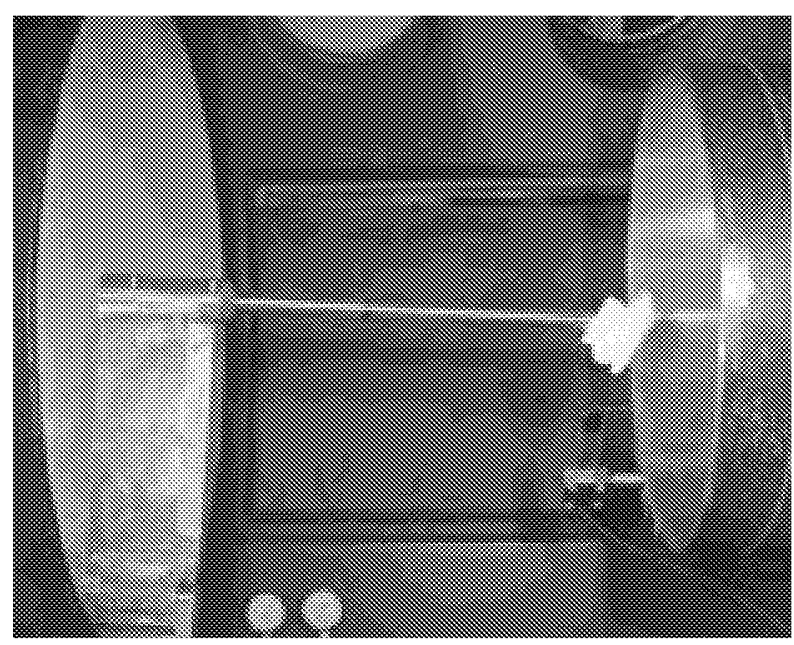

FIGURE 5. MSRO Heating Model Installed in the NASA LaRC 20-Inch Mach $6 \mathrm{CF}_{4}$ Tunnel.

\section{TEST TECHNIQUES}

Advances in image processing technology which have occurred in recent years have made digital optical measurement techniques practical in the wind tunnel. One such optical acquisition method is two-color relativeintensity phosphor thermography (Buck, 1998; Merski, 1998a; 1998b) which has been utilized in several aeroheating tests conducted in the hypersonic wind tunnels of NASA Langley Research Center (Berry et al. 1998a; Horvath et al. 1999; Berry et al. 1998b; Horvath et al. 2000). With this technique, ceramic wind tunnel models are fabricated and coated with phosphors that fluoresce in two regions of the visible spectrum when illuminated with ultraviolet light. The fluorescence intensity is dependent upon the amount of incident ultraviolet light and the local surface temperature of the phosphors. By acquiring fluorescence intensity images with a color video camera of an illuminated phosphor model exposed to flow in a wind tunnel, surface temperature mappings can be calculated on the portions of the model that are in the field of view of the camera. A temperature calibration of the system conducted prior to the study provides the look-up tables that are used to convert the ratio of the green and red intensity images to global temperature mappings. With temperature images acquired at different times in a wind tunnel run, global heat transfer images are computed assuming one-dimensional semi-infinite heat conduction. The primary advantage of the phosphor technique is the global resolution of the quantitative heat transfer data. Such data can be used to identify the heating footprint of complex, three-dimensional flow phenomena (e.g., separation/reattachment, transition fronts, turbulent wedges, boundary layer vortices, etc.) that are extremely difficult to resolve by discrete measurement techniques. Because models are fabricated and instrumented more rapidly and economically, global phosphor thermography has largely replaced discrete heating instrumentation in Langley's $\mathrm{AFC}$. 
Flow visualization in the form of schlieren was used to complement the surface temperature and heating measurements. The LaRC 20-Inch Mach 6 Air and $\mathrm{CF}_{4}$ Tunnels are equipped with a pulsed white-light, Z-pattern, single-pass schlieren system with a field of view encompassing the entire test core. The light sources are pulsed for approximately a $3 \mathrm{~ms}$. Images were recorded on a high-resolution digital camera and enhanced with commercial software.

Surface streamline patterns were obtained using the oil-flow technique. Backup ceramic models were spray-painted black to enhance contrast with the white pigmented oils used to trace streamline movement. A thin basecoat of clear silicon oil was first applied to the surface, and then a mist of pinhead-sized pigmented-oil drops was applied onto the surface. After the model surface was prepared, the model was injected into the hypersonic flow, and the development of the surface streamlines was recorded with a conventional video camera. The model was retracted immediately following flow establishment (and formation of streamline patterns) and post-run digital photographs were taken.

\section{DATA REDUCTION AND UNCERTAINTY}

A 16-bit analog-to-digital facility acquisition system was used to acquire flow condition data. Measured values of $\mathrm{P}_{\mathbf{t}, 1}$ and $\mathrm{T}_{\mathbf{t}, 1}$ are believed to be accurate to within \pm 2 percent.

Heating rates were calculated from the global surface temperature measurements using one-dimensional semi-infinite solid heat-conduction equations, (see Merski, 1998b). As discussed in Merski, (1998b), the accuracy of the phosphor system measurement is dependent on the temperature rise on the surface of the model. For the heating measurements, the phosphor system measurement accuracy is believed to be better than $\pm 8 \%$, and the overall experimental uncertainty of the phosphor heating data due to all factors is estimated to be $\pm 15 \%$. In areas on the model where the surface temperature rise is only a few degrees (i.e. cylinder afterbody, upstream of flow reattachment), the estimated overall uncertainty is on the order of $\pm 25 \%$. Repeatability for the normalized centerline (laminar) heat transfer measurements on the afterbody was found to be generally better than $\pm 8 \%$. Uncertainties in model angle-of-attack and sideslip are believed to be \pm 0.2 degree.

\section{COMPUTATIONAL METHODS}

The Langley Aerothermodynamic Upwind Relaxation Algorithm (LAURA) code (Gnoffo, 1990; Cheatwood and Gnoffo, 1996) was used to provide laminar numerical simulations of the MSRO wake structure at $\mathrm{M}_{\infty}=6 \mathrm{CF}_{4}$ wind tunnel conditions. Grid topology, sensitivity studies, and convergence metrics are discussed in Gnoffo (2001). On the surface, no-slip conditions were applied and model wall temperature was assumed isothermal and set to $300 \mathrm{deg}$ $\mathrm{K}\left(\mathrm{T}_{\mathrm{w}} / \mathrm{T}_{\mathrm{t}}=0.43\right)$.

\section{RESULTS AND DISCUSSION}

\section{Preface}

The heating mappings and distributions in the subsequent sections are presented in the form of a normalized heating coefficient, $h / h_{\text {ref }}$ where $h_{\text {ref }}$ corresponds to the theoretical stagnation point heating at $\alpha=0$ degrees on the model forebody using the method of Fay and Riddell (1958). The reference radius is $45.97-\mathrm{mm}$, which approximates the ellipsoidal nose radius of the AFE forebody in the model plane of symmetry. Shear layer turning angle, which is measured relative to a direction normal to the base plane of the aerobrake (see Fig. 3), is inferred from schlieren images, surface streamline patterns, and local heating. Unless indicated otherwise, all data presented was obtained on models with the aeroshell baseplane configured as open (see Fig. 4).

\section{Shear Layer Identification}

The MSRO is intended to trim between $\alpha=-4$ and +4 degrees during its aerocapture maneuver at Mars. Schlieren images associated with the MSRO flow field (in $M_{\infty}=6$ air at $\operatorname{Re}_{2 \mathrm{D}}=4.15 \times 10^{5}$ ) are presented in Fig. 6 , for a range of angle of attack $(-5<\alpha<+10$ degrees $)$. 


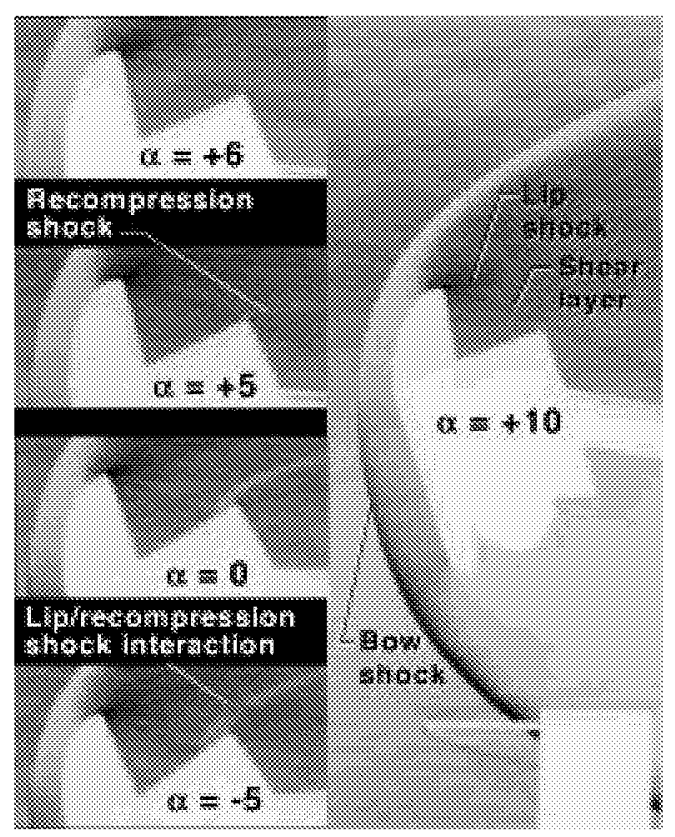

FIGURE 6. Schlieren Images Indicating General Flow Features Observed from MSRO Near Wake Flowfield. $M_{\infty}=6$, air, $\operatorname{Re}_{2 \mathrm{D}}=415,000,-5<\alpha<+10$ degrees.

In the sequence of images, a weak lip shock associated with the rapid over expansion and subsequent recompression around the aerobrake shoulder is evident, in addition to a relatively thin free shear layer. While not attempted in the present study, $M_{\infty}=6$ air flow field surveys in the base region of a similar blunt body (Horvath et al., 1996) have correlated wake lip shock and shear layer boundaries inferred from pitot pressure profiles to visual locations inferred from schlieren images. The MSRO schlieren images shown in Fig. 6, indicate that at angles of attack larger than +6 degrees, the afterbody upper symmetry plane (surface opposite the EEV and retrieval hardware) avoids direct shear layer impingement for this condition. As the model angle of attack is decreased, the onset of shear layer impingement is observed to occur (in air) between $\alpha=+6$ and +5 degrees, and is indicated by a weak recompression shock at the reattachment point near the end of the cylindrical afterbody. The shear layer impingement point progressively moves towards the aerobrake base (and the strength of the recompression shock increases) as the vehicle angle of attack is decreased to $\alpha=-5$ degrees. At the limiting incidence angle of $\alpha=-5$ degrees, an interaction of the lip shock with the afterbody recompression shock is observed near the aft corner of the afterbody. Shear layer impingement on the EEV and retrieval hardware are not observed in $M_{\infty}=6$ air for $-5<\alpha<+10$ degrees. The sensitivity of the schlieren system is insufficient to detect the wake shear layer in the $\mathrm{CF}_{4}$ facility due to the low density of the base region flow.

Heating distributions obtained in $\mathrm{M}_{\infty}=6$ air and $\mathrm{CF}_{4}$ along the cylinder afterbody at several time intervals are used to determine when the base flow is established. Although some degree of wake flow unsteadiness is inherent, the shear layer position is typically stable within the framing rate (30 frames/sec.) and spatial resolution of the schlieren video imagery

\section{Shear Layer Impingement}

Shear layer impingement will result in localized surface pressure and convective heating increases. Typical surface streamlines and heating distributions on the MSRO afterbody in the presence of shear layer impingement are shown in Figs. 7 and 8 at $\alpha=-4$ degrees for $M_{\infty}=6$ air and $R_{2 D}=6.5 \times 10^{4}$. Similar trends were observed at corresponding conditions in $\mathrm{M}_{\infty}=6 \mathrm{CF}_{4}$. The pressure rise due to reattachment and downstream recompression contributed to the reversal of the flow back towards the open forebody base as inferred from the surface streamline patterns (see Fig. 7). The location of the dividing streamline delineating the entrained recirculating base flow from the flow continuing downstream is evident in this figure. As discussed in a subsequent section, this reversed flow was often observed to produce complex recirculation patterns on the forebody base presumably due to primary and secondary vortices. 
The corresponding surface heating (see Fig.8), indicates that the local impingement heating at this condition approached $65 \%$ of the reference forebody stagnation point value; heating levels upstream of the attachment location and on the base were under $5 \%$ of the reference stagnation value. Regions of flow reattachment inferred from heating patterns on the afterbody side is not evident for sideslip angles up to 6 degrees (not shown).

MSRO afterbody wall temperatures in $\mathrm{M}_{\infty}=6$ air obtained 5 seconds after model exposure were generally uniform $\left(\mathrm{T}_{\mathrm{w}}=317 \mathrm{deg} . \mathrm{K} ; \mathrm{T}_{\mathrm{w}} / \mathrm{T}_{\mathrm{t}}=0.61\right)$ in locations away from impingement. At higher Reynolds numbers, localized turbulent heating near impingement produced wall temperatures as high as 383 degree. $\mathrm{K}\left(\mathrm{T}_{\mathrm{w}} / \mathrm{T}_{\mathrm{t}}=0.74\right)$ with peak heating levels that approached $75 \%$ of the reference stagnation value.

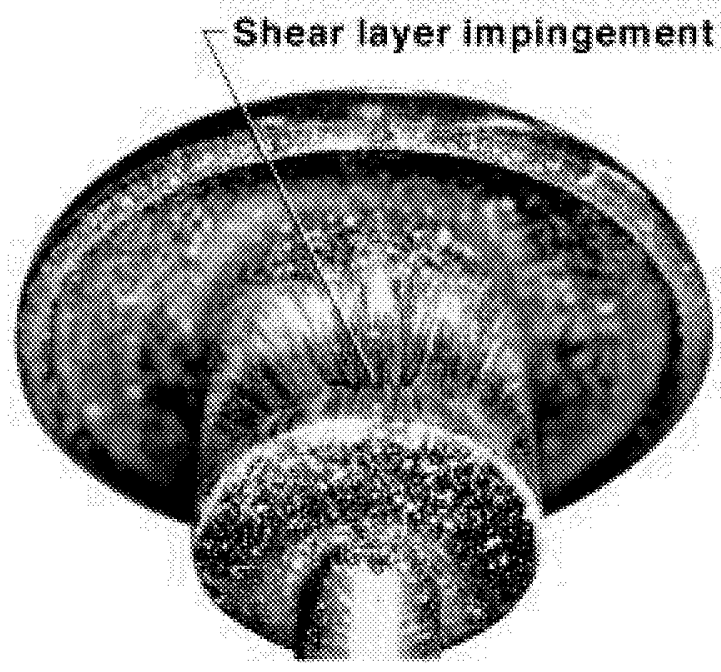

FIGURE 7. Typical Surface Streamlines on MSRO Afterbody in the Presence of Shear Layer Impingement. $M_{\infty}=6$, air, $\operatorname{Re}_{2 D}=415,000, \alpha=-4$ degrees

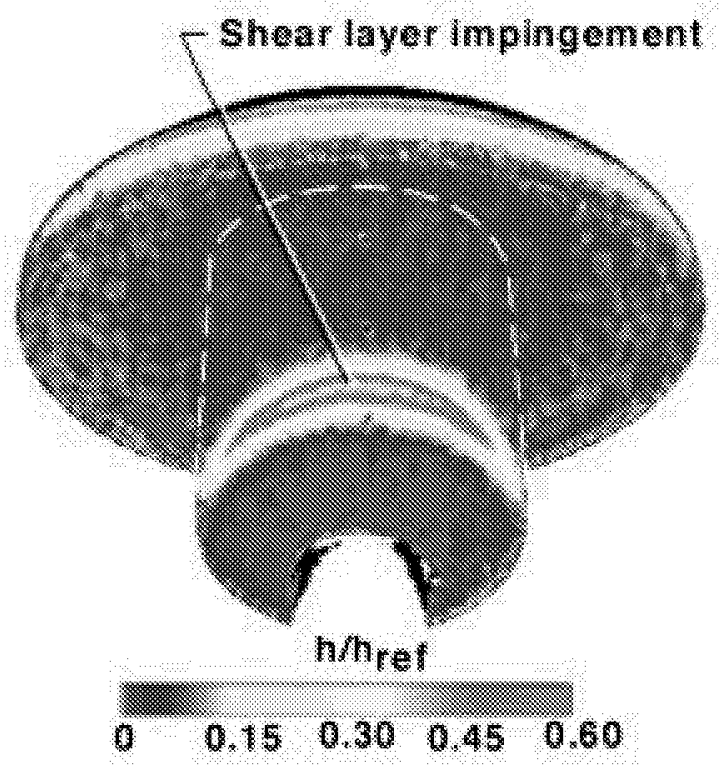

FIGURE 8. Typical Surface Heating on MSRO Afterbody in the Presence of Shear Layer Impingement. $\mathrm{M}_{\infty}=6$, air, $\operatorname{Re}_{2 \mathrm{D}}=415,000, \alpha=-4$ degrees.

\section{Reynolds Number Effects}

Because experimental evidence revealed shear layer impingement at trim angles of attack, it became necessary to quantify impingement heating levels and thus identify the state of the prevailing interaction (laminar, transitional, or turbulent). As discussed in detail in Wuerer (1965), separated flows are largely characterized by the prevailing boundary layer or shear layer state. Differences in laminar and turbulent separated regions are primarily attributed to enhanced mixing (greater effective momentum transfer) associated with turbulence. The presence of a transitional shear layer often leads to much higher peak heating at reattachment than if the separated flow is entirely laminar or turbulent (Horvath et al., 1996; Barker and Martin, 1966). While edge conditions (M, Re, and $\gamma$ ) at the point of boundary layer separation determine the initial shear layer turning angle, the state of the interaction (reattachment) downstream also effects the extent (and degree) of unsteadiness of the reversed flow. Thus, a secondary objective of the experimental program was to produce both a laminar and turbulent interaction from which comparisons to numerical solutions could be made. Confidence levels associated with numerical simulation of separated laminar flows are generally lower than for laminar attached flows. As discussed by Nance and Horvath (1997), the additional complexity of accurately modeling transitional or turbulent separated flow has also proven to be a challenge (ironically, it is the laminar wake interaction that is often difficult to achieve in conventional ground based hypersonic wind tunnel due to facility operational limitations at low Reynolds numbers).

The $\mathrm{M}_{\infty}=6 \mathrm{CF}_{4}$ tunnel was initially attractive from the perspective of testing in a gas with a low ratio of specific heats $(\gamma)$ - as is encountered in hypervelocity flight. In addition, the facility provides the best opportunity from which to maintain a laminar interaction since it operates at low pressures (and hence, Reynolds numbers). 
Normalized heating along the MSRO cylindrical afterbody is shown in Fig. 9 at $\alpha=-4$ degrees for $\mathrm{M}_{\infty}=6 \mathrm{CF}_{4}$ over a range of post normal shock Reynolds numbers $\left(\operatorname{Re}_{2 \mathrm{D}}=1,420\right.$ to 52,442 ). The abscissa of Fig. 9 (and all subsequent afterbody heating distributions) refers to the running length along the cylinder non-dimensionalized by the forebody diameter, originating at the aft comer and running forward towards the aerobrake base. The relatively small invariance in the measured magnitude and spatial location of the reattachment heating peak for $\operatorname{Re}_{2 \mathrm{D}}=1,420$ to 3,946 is interpreted as evidence of a laminar interaction. An increase (and subsequent movement) of peak reattachment heating towards the aerobrake base for $\mathrm{Re}_{2 \mathrm{D}}>3,946$ suggested a non-laminar interaction (Horvath et al., 1996; Hollis, 1996; Berger, 1971) and/or an increase in the shear layer turning angle. The effects of Reynolds number on shear layer turning angle will be discussed in a subsequent section.

The $\mathrm{M}_{\infty}=6$ air tunnel provides a two order-of-magnitude increase in post-normal shock Reynolds number over the $\mathrm{CF}_{4}$ data. Normalized heating along the MSRO cylindrical afterbody is shown in Fig. 10 at $\alpha=-4$ degrees in $\mathrm{M}_{\infty}=6$ air for $\mathrm{Re}_{2 \mathrm{D}}=36,700$ to 415,000 . A small overlap in terms of post-normal shock Reynolds number exists between the two facilities. Qualitatively, the magnitude of the measured impingement heating peak in $\mathrm{M}_{\infty}=6$ air at the lowest Reynolds number $\left(\operatorname{Re}_{2 \mathrm{D}}=36,700\right.$ - Fig. 10 ) is consistent with that measured at the highest Reynolds number $\left(\operatorname{Re}_{2 \mathrm{D}}=52,442-\mathrm{Fig} .9\right)$ in $\mathrm{M}_{\infty}=6 \mathrm{CF}_{4}$. The continuation of the forward movement of the local reattachment heating peak in $M \infty=6$ air toward the aerobrake base is evident. The continual rise in the heating peak to $h / h_{\text {ref }}=0.66$, as measured at $\operatorname{Re}_{2 \mathrm{D}}=65,000$ and the subsequent drop to $\mathrm{h} / \mathrm{h}_{\mathrm{ref}}=0.60$ for $\mathrm{Re}_{2 \mathrm{D}}=123,000$, (see Fig. 10), is interpreted as the condition at which the transitional shear layer becomes fully turbulent. It is suggested that this situation is analogous to the transitional "overshoot" phenomenon commonly observed with attached wall boundary layers (where it has been conjectured that the larger vortical length scales associated with transitional flows are more effective at momentum transfer than the finer scales found in a fully turbulent situation). In the postulated turbulent regime, a rise in the non-dimensional heating peak to 0.73 for $R_{2 D}=415,000$ was measured in $M_{\infty}=6$ air. $A$ Reynolds number collapse of turbulent heating data is not observed when normalized with a laminar reference value.

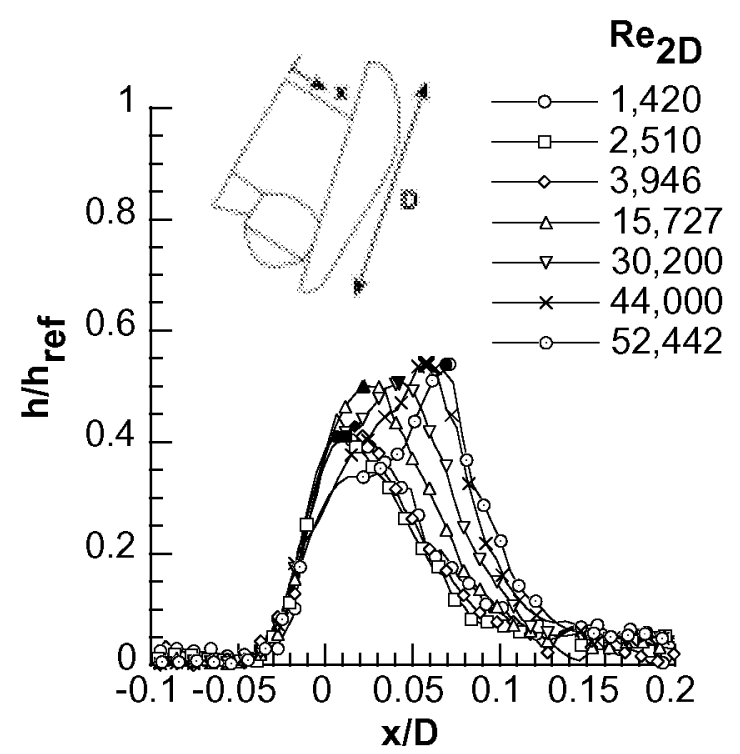

FIGURE 9. Effect of Reynolds Number on Normalized Impingement Zone Heating Along MSRO Afterbody. $\mathrm{M}_{\infty}=6, \mathrm{CF} 4, \rho_{2} / \rho_{\infty}=12, \alpha=-4$ degrees.

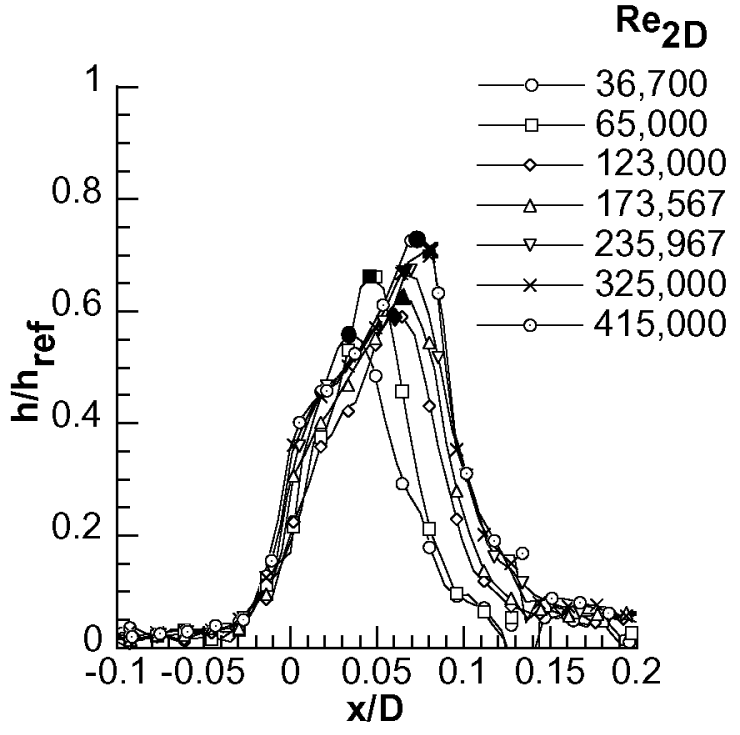

FIGURE 10. Effect of Reynolds Number on Normalized Impingement Zone Heating Along MSRO Afterbody. $\mathrm{M}_{\infty}=6$, air, $\rho_{2} / \rho_{\infty}=5, \alpha=-4$ degrees.

The approximate range of $\mathrm{Re}_{2 \mathrm{D}}$ at which the wake interaction is postulated to go from a laminar to a transitional state, and from a transitional to a turbulent state are presented in Fig. 11. In this figure, the local heating peak at reattachment has been plotted as a function of $\operatorname{Re}_{2 \mathrm{D}}$ for both $\mathrm{M}_{\infty}=6$ air and $\mathrm{CF}_{4}$. The relatively small invariance in the measured magnitude of the reattachment heating peak for $\operatorname{Re}_{2 \mathrm{D}}=1,420$ to 3,946 is interpreted as evidence of a laminar interaction for $\mathrm{M}_{\infty}=6 \mathrm{CF}_{4}$. The present data suggest a non laminar wake for $\operatorname{Re}_{2 \mathrm{D}}>3,946$. In perspective, the post-normal shock Reynolds number for Mars entry at peak heating conditions is expected to be near $\mathrm{Re}_{2 \mathrm{D}}=83,000$. While the shear layer transition onset Reynolds number should not be applied directly to flight due 
primarily to the adverse effect of tunnel noise, the ground based measurements are considered conservative and suggest the possibility of a non laminar wake during the aerocapture maneuver.

A limited literature search yielded several empirically derived correlations from which to determine the onset of wake flow transition. In a qualitative attempt to classify the present $\mathrm{M}_{\infty}=6 \mathrm{CF}_{4}$ results as laminar, the data are presented in terms of, (and compared against), a simple unified wake transition correlation proposed by Zeiberg (1964) in Fig. 12. The parameters for the original correlation in Zeiberg (1964) are freestream length Reynolds number (the length based upon the axial wake transition location relative to the base) and freestream Mach number. The correlation was developed from a large experimental database for cones, spheres, wedges, and sphere-cones that were tested over a range of supersonic and hypersonic Mach numbers. The potential effects of bluntness and body shape on wake transition were recognized by Zeiberg (1964) and the length Reynolds number parameter was modified to include the square of the ratio of the freestream Mach number to a local wake Mach number. In terms of the correlation, the present $\mathrm{M}_{\infty}=6 \mathrm{CF}_{4}$ condition (interpreted as laminar for $\mathrm{Re}_{2 \mathrm{D}}=1,420$ ) is an order of magnitude or more below the specified criteria for wake transition. The local wake Mach number for the present results was determined from laminar prediction corresponding to a location just outside of the recirculating base flow (near shear layer impingement). The size of the symbols, (Fig. 12), are indicative of the dependence of the correlation parameter to the variation in Mach number as computed in this region. The transition length was assumed to be the axial distance of the aft cylinder (presumably where transition was observed) to the MSRO base. The $\mathrm{M}_{\infty}=6 \mathrm{CF}_{4}$ results which were interpreted as transitional $\left(\operatorname{Re}_{2 \mathrm{D}}=52,442\right)$ were significantly closer to the correlation criteria for wake transition.

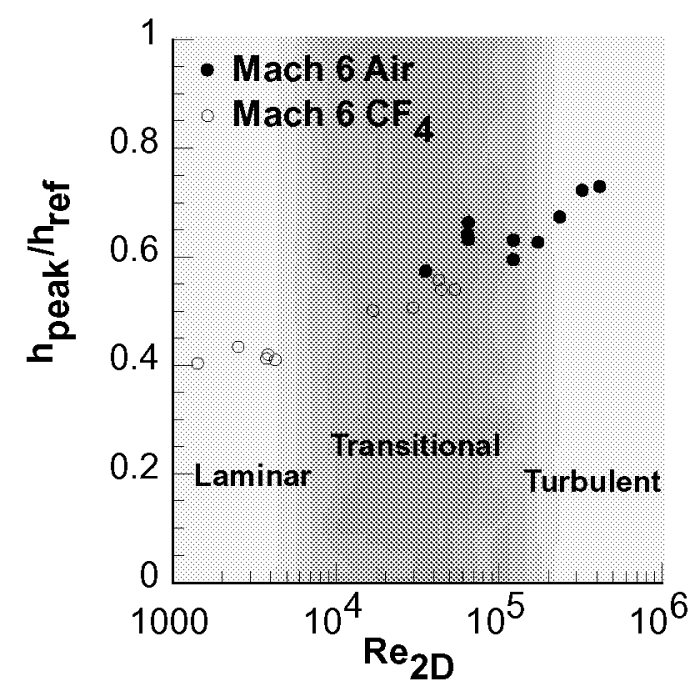

FIGURE 11. Effect of Reynolds Number on Normalized Impingement Heating Peak on MSRO Afterbody. $\mathrm{M}_{\infty}=6$, air and $\mathrm{CF}_{4}, \alpha=-4$ degrees.

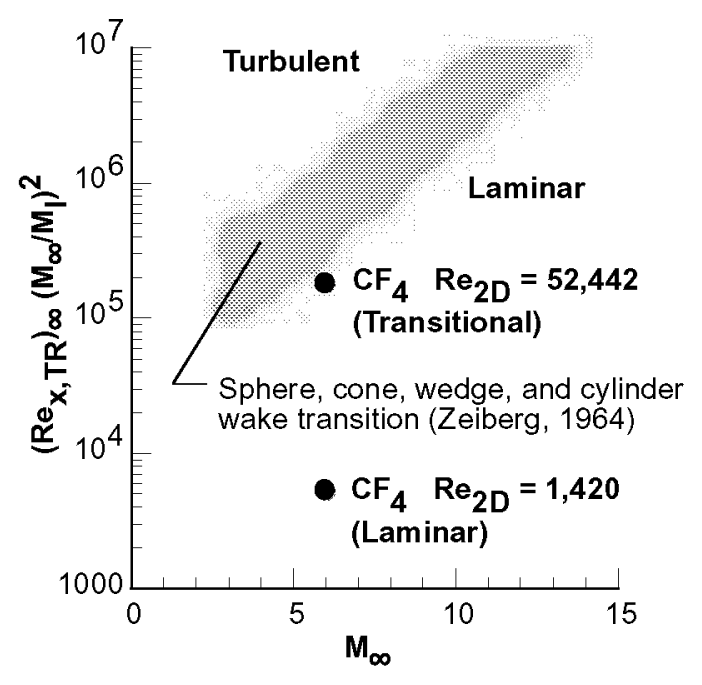

FIGURE 12. Comparison of Present Results to a Unified Wake Transition Correlation (Zeiberg, 1964). $\mathrm{M}_{\infty}=6$, $\mathrm{CF}_{4}, \alpha=-4$ degrees.

\section{Base Effects}

It is generally recognized that the presence of a support sting will have an effect on the base flow characteristics of a blunt body in hypersonic flow. A limited data set was taken to assess support interference effects. Experimentally, the sensitivity of the MSRO afterbody heating to the potential effects of a cylindrical model support sting was assessed for sting-to-model forebody diameter ratios $\left(\mathrm{d}_{\mathrm{s}} / \mathrm{d}_{\mathrm{f}}\right)$ of 0.19 and 0.32 . Fig. 13 shows that at a transitional Reynolds number $\left(\operatorname{Re}_{2 \mathrm{D}}=36,700\right)$, for $\mathrm{M}_{\infty}=6$ air at $\alpha=-4$ degrees, an increase in the support sting diameter produces no measurable effect on impingement location and associated reattachment heating levels. Transitional data for 
$\mathrm{M}_{\infty}=6 \mathrm{CF}_{4}$ (not shown) supports a similar conclusion. Comparison of the data in Fig. 13 also serves to indicate the level of repeatability associated with the wake heating measurements.

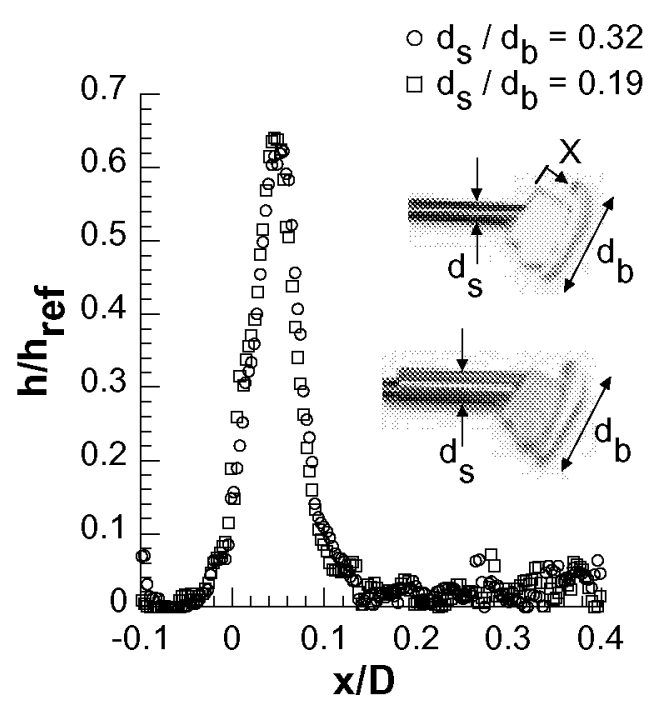

FIGURE 13. Effect of Support Sting Diameter on Normalized MSRO Transitional Impingement Zone Heating. $M_{\infty}=6$, air, $\operatorname{Re}_{2 \mathrm{D}}=36,700, \alpha=-4$ degrees.

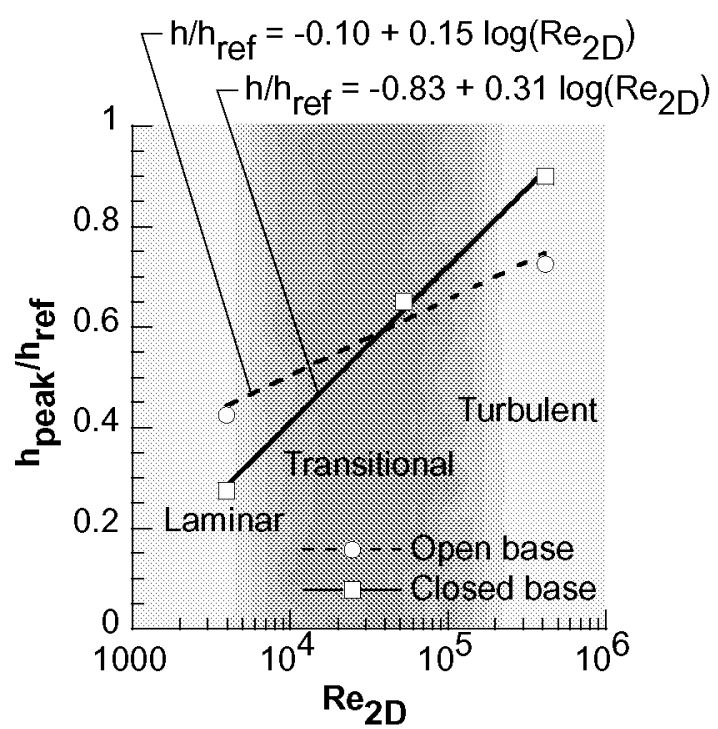

FIGURE 14. Effect of Open and Closed MSRO Base Plane on Normalized Impingement Zone Heating. $\mathrm{M}_{\infty}=6$, $\alpha=-4$ degrees.

As shown in Fig. 14, the baseplane geometry (open and closed - see Fig. 4) and Reynolds number have a pronounced effect on the magnitude of the nondimensional peak heating associated with shear layer impingement on the MSRO afterbody. For a non laminar base flow $\left(\operatorname{Re}_{2 \mathrm{D}}>3,946\right)$, reattachment heating increases linearly with the $\log$ of the post shock Reynolds number based on body diameter. Logarithmic curve fits to the data plotted in semilog form indicates the rate change of normalized heating associated with the closed base is approximately twice that of the open base. For a laminar wake condition $\left(\operatorname{Re}_{2 \mathrm{D}}=3,946\right)$ in $\mathrm{M}_{\infty}=6 \mathrm{CF}_{4}$ at $\alpha=-4$ degrees, the peak heating associated with the closed (or filled baseplane) is approximately $60 \%$ lower (from $\mathrm{h} / \mathrm{h}_{\mathrm{ref}}=0.43$ to 0.27 ) relative to that obtained with the open base. In contrast, for a turbulent wake condition $\left(\operatorname{Re}_{2 \mathrm{D}}=415,000\right)$ in $\mathrm{M}_{\infty}=6$ air the afterbody peak heating associated with the closed baseplane is approximately $23 \%$ higher (from $\mathrm{h} / \mathrm{href}=0.73$ to 0.90 ) than that measured with the open base. When the shear layer state is interpreted as transitional in $\mathrm{M}_{\infty}=6$ air $\left(\operatorname{Re}_{2 \mathrm{D}}=52,442\right.$; see also Fig. 16), no change in peak heating magnitude for the open and closed baseplanes is measured, (a similar conclusion was obtained for transitional measurements in $\mathrm{M}_{\infty}=6 \mathrm{CF}_{4^{-}}$not shown). The turbulent wake associated with the closed MSRO base represents a worst case scenario in terms of afterbody heating where localized values at reattachment approached forebody stagnation levels. While the reattachment heating levels exhibited a sensitivity to an open or closed baseplane, the spatial location of the heating peak in terms of $\mathrm{x} / \mathrm{D}$ (and hence, shear layer turning angle) did not as shown in Figs. 15, 16, and 17 for laminar, transitional, and turbulent Reynolds numbers, respectively. The physical explanation of this observation is not clear at the present time but the increased reattachment heating measured in the absence of increased shear layer turning suggest that the base modifications have produced local flow gradient changes within the shear layer itself which result in increased heating. 


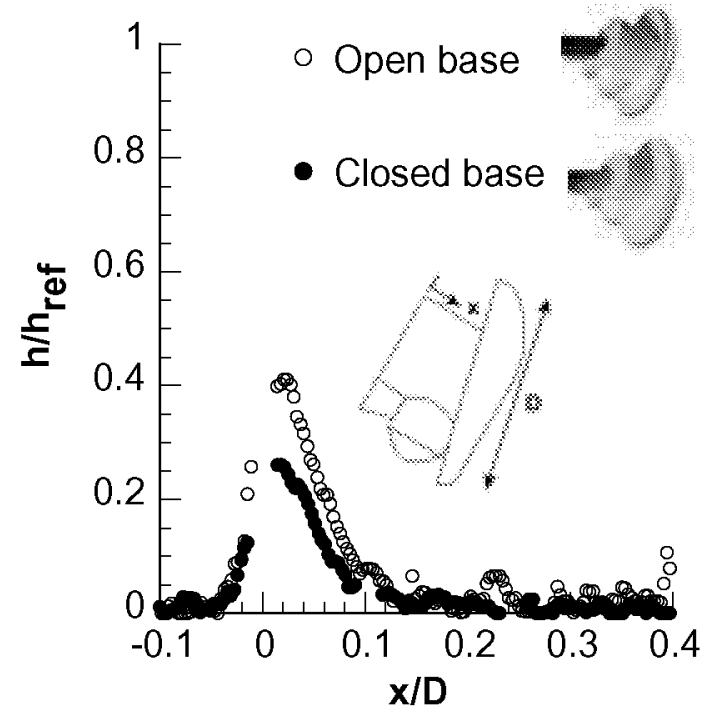

FIGURE 15. Effect of Open and Closed MSRO Base Plane on Normalized Laminar Impingement Zone Heating. $\mathrm{M}_{\infty}=6, \mathrm{CF}_{4}, \mathrm{Re}_{2 \mathrm{D}}=3,946, \alpha=-4$ degrees.

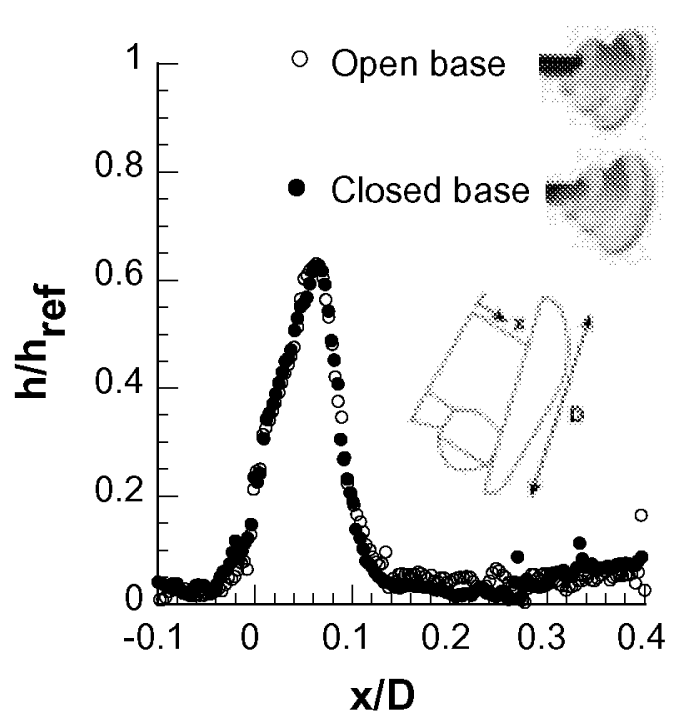

FIGURE 16. Effect of Open and Closed MSRO Base Plane on Normalized Transitional Impingement Zone Heating. $M_{\infty}=6$, air, $\operatorname{Re}_{2 \mathrm{D}}=52,442, \alpha=-4$ degrees.

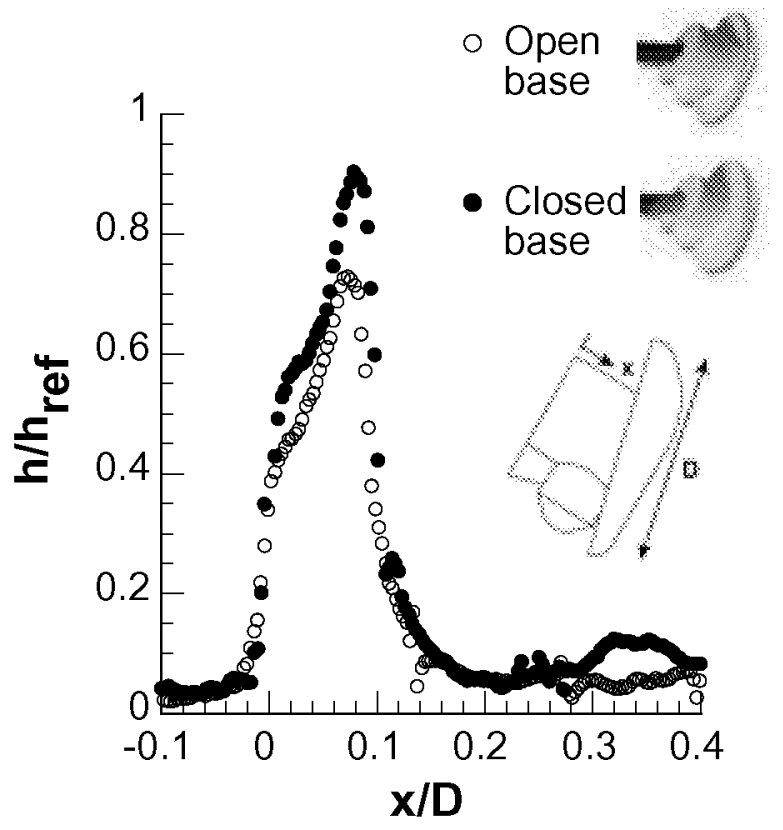

FIGURE 17. Effect of Open and Closed MSRO Base Plane on Normalized Turbulent Impingement Zone Heating. $M_{\infty}=6$, air, $\operatorname{Re}_{2 \mathrm{D}}=415,000, \alpha=-4$ degrees. 


\section{Shear Layer Turning Angle Characteristics}

From a practical perspective, the usable volume for payload placement behind an aerobrake is generally constrained by the position of the wake free shear layer. The wake boundaries from which the MSRO afterbody was initially designed were inferred from a correlation derived from a series of ground-based blunt body tests at $M_{\infty}=6$ and 10 air and numerical flight prediction (Gnoffo, 1992). In this correlation, measured and computed shear layer deflection angles and vehicle angle of attack are expressed relative to a direction normal to the given aerobrake baseplane. A linear relationship was identified between the shear layer turning angle $\left(\theta_{\text {eff }}\right)$ and the effective angle of attack ( $\left.\alpha_{\text {eff }}\right)$

The shear layer turning angle (as a function of effective angle of attack) inferred from the present heating, surface streamline, and shock pattern measurements in $\mathrm{M}_{\infty}=6$ air and $\mathrm{CF}_{4}$ are presented in Fig. 18 and Fig. 19, respectively. For clarification purposes, the ground based results from Gnoffo, (1992) are presented in these figures in the form of a shaded band. Consistent with the methodology of Gnoffo, (1992), the shear layer deflection angles are measured relative to a straight line drawn from the model base corner to the measured location of the attachment point as inferred from surface streamline patterns, schlieren images, and the location of peak heating using phosphor thermography.

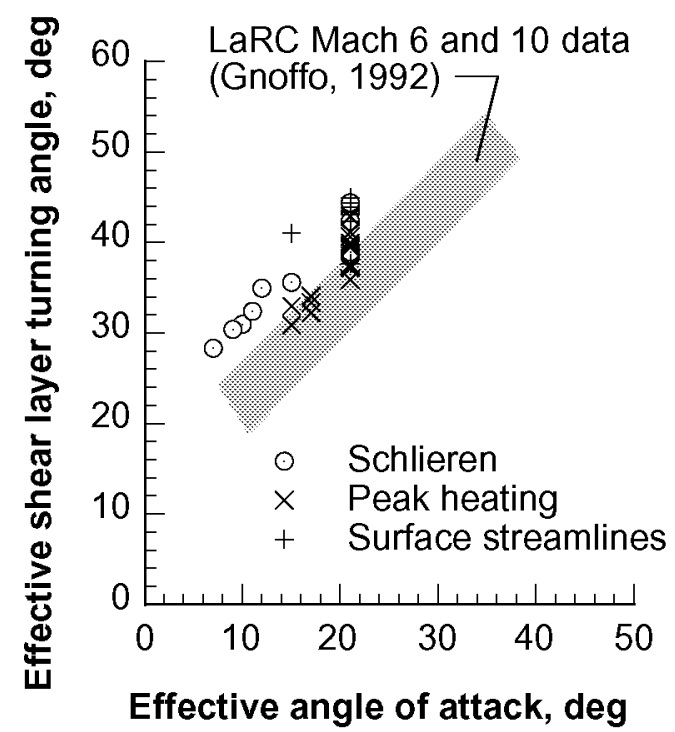

FIGURE 18. MSRO Shear Layer Turning Angle as a Function of Effective Angle of Attack. $\mathrm{M}_{\infty}=6$, air, $\operatorname{Re}_{2 \mathrm{D}}=36,700$ to 415,000 .

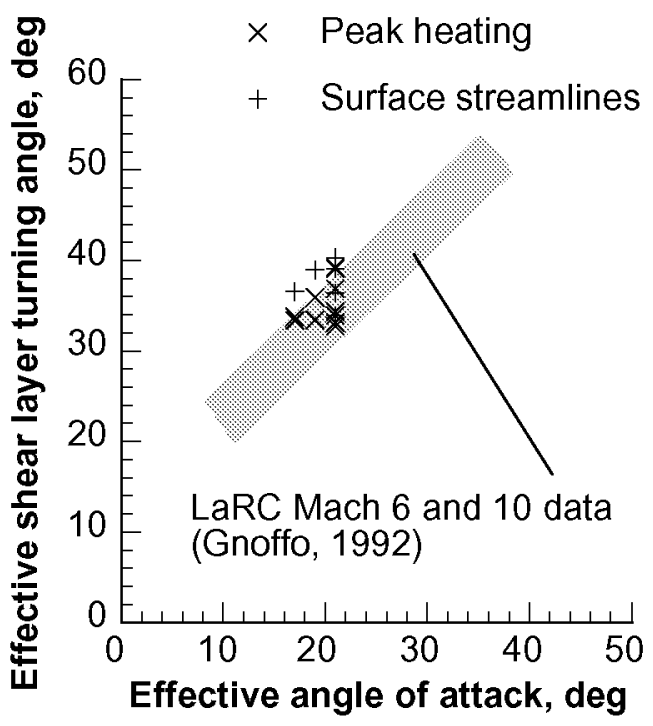

FIGURE 19. MSRO Shear Layer Turning Angle as a Function of Effective Angle of Attack. $\mathrm{M}_{\infty}=6, \mathrm{CF}_{4}$, $\operatorname{Re}_{2 \mathrm{D}}=1,420$ to 52,442 .

The present MSRO results obtained with the open base plane exhibit the same general linear trend as the correlation of Gnoffo, (1992). The turning angle inferred from the $\mathrm{CF}_{4}$ heating and streamline measurements (see Fig. 19), compare well with the correlation. In the present data, the variation of the turning angle for each effective angle of attack has been attributed to transitional/turbulent Reynolds number effects discussed earlier. That is, for a nonlaminar interaction, an increase in Reynolds number moves the impingement location towards the aerobrake base, implying a larger turning angle. The effect of Reynolds number on shear layer turning for a laminar interaction is inconclusive due to the limited range of Reynolds number for laminar $\mathrm{CF}_{4}$ data. The $\mathrm{M}_{\infty}=6$ air results, Fig. 18 , indicate a bias towards a larger turning angle relative to the original correlation and this is, in part, attributed to the greater turbulent Reynolds number range achieved in the present tests.

For a given $\mathrm{Re}_{2 \mathrm{D}}$ corresponding to a non-laminar shear layer, the shear layer turning angle as inferred from surface streamlines or shock patterns is generally greater than that determined via the peak heating location. Shear layer turning angles as a function of $\mathrm{Re}_{2 \mathrm{D}}$ for $\alpha=-4$ degrees in $\mathrm{M}_{\infty}=6$ air and $\mathrm{CF}_{4}$ are presented in Fig. 20 and Fig. 21, respectively. For the laminar $\mathrm{M}_{\infty}=6 \mathrm{CF}_{4}$ condition $\left(\mathrm{Re}_{2 \mathrm{D}}=1,420\right.$ to 3,946$)$, the turning angle associated with peak heating on the afterbody is within one degree of that inferred from surface streamlines or shock patterns, as shown in 
Fig. 21. For transitional/turbulent conditions in $M_{\infty}=6$ air $\left(\operatorname{Re}_{2 \mathrm{D}}>3,946\right.$, Fig. 20), this difference is as large as four degrees. As indicated by the data in Figs. 20 and 21 , the turning angle for a transitional/turbulent interaction is larger than its laminar counterpart. As inferred from this data, the transitional/turbulent heating maximum on the cylinder afterbody $\left(\operatorname{Re}_{2 \mathrm{D}}>3,946\right)$ is located downstream of the reattachment point as determined from surface streamlines or shock patterns.

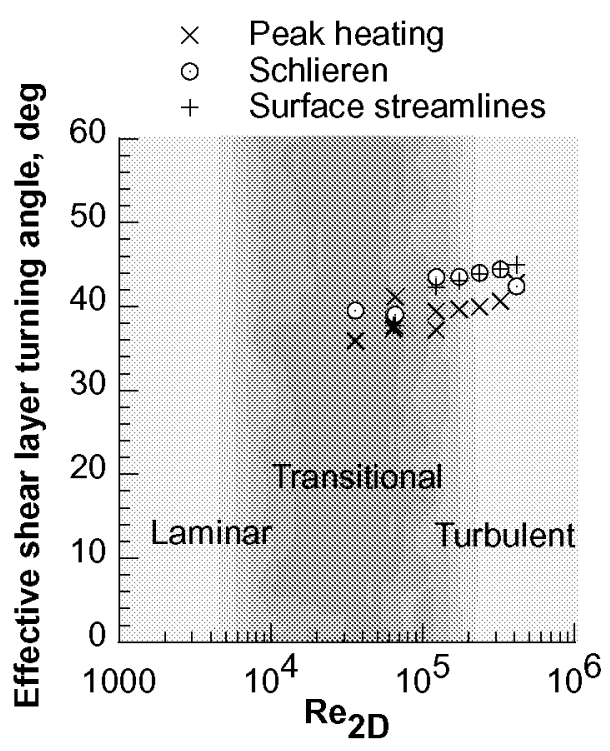

FIGURE 20. MSRO Shear Layer Turning Angle as a Function of Reynolds Number. $\mathrm{M}_{\infty}=6$, air, $\alpha=-4$ degrees.

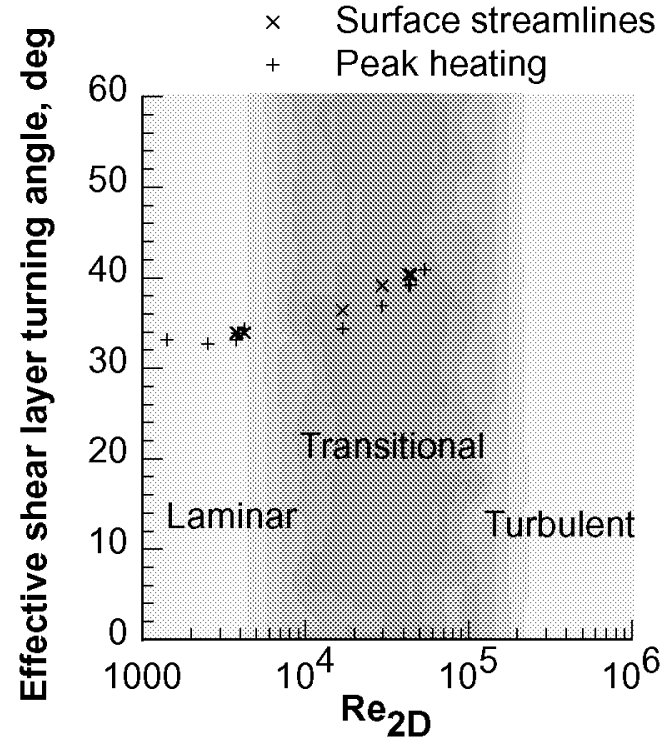

FIGURE 21. MSRO Shear Layer Turning Angle as a Function of Reynolds number. $\mathrm{M}_{\infty}=6, \mathrm{CF}_{4}, \alpha=-4$ degrees.

It was concluded in Gnoffo, (1992) that no significant effects due to $\mathrm{M}_{\infty}, \mathrm{Re}_{2 \mathrm{D}}$, or vehicle forebody geometry were observed in the ground-based test data that the shear layer turning angle correlation was derived from. Slightly larger shear layer turning angles were predicted at flight conditions and it was suggested that this could have been a gas chemistry effect. As discussed in Gnoffo, (1992), the severe compression in the forebody shock layer and the subsequent rapid expansion into the wake are characterized by high temperature, thermo-chemical nonequilibrium processes. In contrast to quantifying the aerodynamic effects associated a real gas, the applicability of the present MSRO simulation tests in $\mathrm{CF}_{4}$ are not certain regarding the characterization of blunt body wake flow. From an aerodynamic perspective, it has been shown (Brauckmann, 1994) that the increments and trends provided by real gas simulation tests in air and $\mathrm{CF}_{4}$ are applicable to flight provided that (1) the vehicle aerodynamics are dominated by the windward surface pressure (shear stress contributions negligible), (2) $\gamma$ within the flight windward shock layer does not significantly vary spatially, and (3) $\gamma$ within the flight windward shock layer is close in magnitude to that produced in $\mathrm{CF}_{4}(\gamma=1.1)$. Despite ground based testing simulation issues and geometrical afterbody differences from those configurations used to define the turning angle correlation of Gnoffo, (1992), the present MSRO laminar $\mathrm{CF}_{4}$ data has suggested the general applicability of the correlation for predicting wake shear layer turning for initial design estimates. If shear layer transition in flight is anticipated (i.e. via forebody ablation or surface roughness) a larger turning angle should be expected.

The intent of the baseline MSRO afterbody design was to avoid impingement at trim angles of attack. The present results along with recent hypersonic tests (Chanetz, 2001; Giraud, 2001) conducted in European facilities (in air and $\mathrm{CO}_{2}$ ) have all indicated flow impingement on the MSRO afterbody near trim conditions. Flight computations (Glass and Gnoffo, 2000; Gnoffo, 2001; Chanetz, 2001) have indicated impingement as well. These experimental and computational results reveal the presence of impingement which will necessitate the use of a supplemental thermal protection system such as an afterbody shield discussed in Chanetz, (2001) should the afterbody geometry not change. In hindsight, it appears that the early engineering estimates of the MSRO wake closure characteristics (to avoid shear layer impingement) were not conservative enough. For design purposes, a shear layer turning angle of 30 degrees (see Fig. 22) was originally assumed based upon an effective angle of attack of $15(\alpha=+2$ degrees) degrees. As aerodynamic performance of the aerobrake during an aeropass maneuver was refined to include 
dispersions, the effective angle of attack to trim the MSRO was increased to 19 degrees ( $\alpha=-2$ degrees) and later to 21 degrees $(\alpha=-4$ degrees). Based upon the correlation of Gnoffo, (1992), the projected shear layer turning angle relative to the baseplane would increase to approximately 39 degrees. The relationship of these turning angles relative to the MSRO afterbody is shown, Fig. 22. As inferred from the correlation, impingement on the afterbody would occur for effective angles of attack of 19 and 21 degrees. If shear layer impingement is present at flight conditions and adequate thermal protection is not possible, a small rotation or lateral displacement of the afterbody in the plane of symmetry or scarfing the aft comer could provide a means to avoid impingement as shown, Fig. 23. While possibly mitigating localized heating, afterbody displacement or scarfing would affect the vehicle c.g. location and the MSRO aerodynamics. Alternatively, an appropriate modification to the MSRO base geometry near the MSRO shoulder (see Chanetz, 2001) could delay flow separation from the base and prevent local impingement heating to the orbiter afterbody. A computational study by Dogra et al. (1995), investigated the effects of afterbody geometry on wake closure and base heating for a spherically blunted cone. Relative to a cylindrical afterbody, Dogra (1995) determined that a conical afterbody moved base flow separation downstream thereby eliminating direct shear layer impingement that was present on the cylindrical base. As expected, the acreage heating associated with the conical afterbody was higher relative to that predicted on the cylindrical afterbody. Thus, while base modifications may prevent local heating from direct flow impingement, increased acreage heating on the base may result in additional thermal protection and add undesirable mass to the orbiter aft of the vehicle c.g. location.

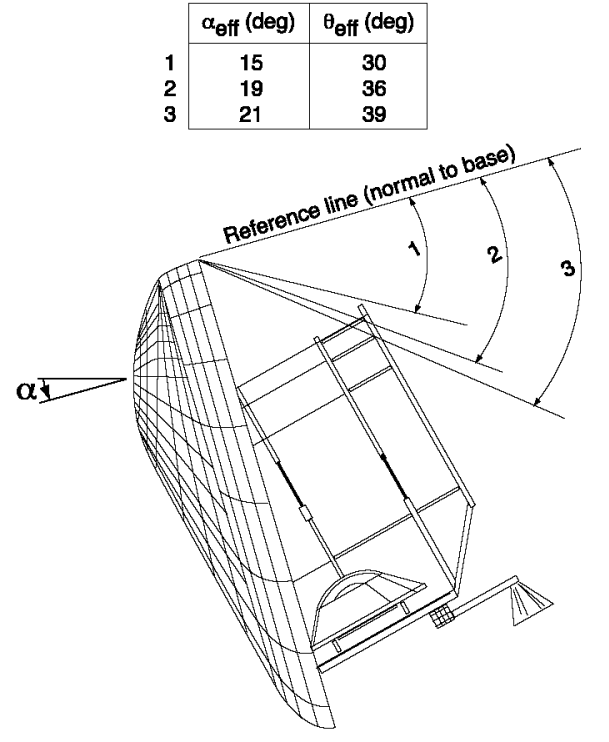

FIGURE 22. Estimated Position of MSRO Wake Shear Layer Relative to the Afterbody for Various Effective Angles of Attack.

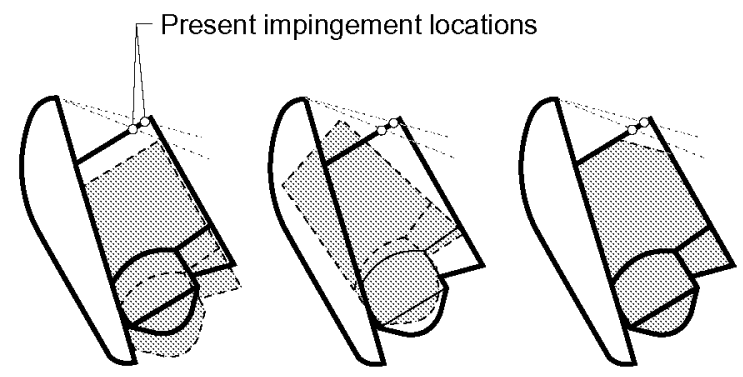

Afterbody lateral displacement

Afterbody rotation

Scarfing the aft corner

FIGURE 23. Potential Configuration Modifications to Avoid Shear Layer Impingement on MSRO Afterbody.

\section{Comparison to Measurement}

Accurate, quantitative measurement and numerical simulation of laminar, transitional, and turbulent separated/reattaching flows remains a challenge. Due to the operating range of most continuum hypersonic facilities, maintaining a laminar shear layer in regions of strong expansion (such as that encountered in the near wakes of blunt bodies) has in the past proven difficult (Horvath, 1996; Horvath, 1997). The influence of tunnel noise on shear layer transition is not well understood. When turbulent interactions are present, numerical turbulence models play a crucial role in the simulation of these non-laminar flows where separation, shock-boundary layer interaction, and flow reattachment are present (Horvath, 2000). For the simpler laminar interactions, which avoid turbulence modeling, grid issues related to resolving near wake flow features such as the free shear layer persist (Hollis, 1996).

The present experiments were performed in an effort to provide benchmark data for complex laminar/turbulent separated flows. Comparison of laminar heating prediction (via the LAURA code) to experimental measurement 
along the MSRO afterbody near impingement is shown in Fig. 24, for $M_{\infty}=6 \mathrm{CF}_{4}\left(\operatorname{Re}_{2 \mathrm{D}}=3,946\right)$. Measurement and prediction correspond to an open base. As discussed previously, the abscissa of this figure refers to the running length along the cylinder non-dimensionalized by the forebody diameter, originating at the aft corner and running forward towards the aerobrake base. The laminar experimental results indicate an impingement heating peak of $\mathrm{h} / \mathrm{h}_{\mathrm{ref}}=0.41$ at $\mathrm{x} / \mathrm{D}=0.02$ in close proximity to the afterbody corner. Numerical results obtained on both grids indicate a local heating spike at the afterbody corner $(\mathrm{x} / \mathrm{D}=0)$ where there is a rapid thinning of the boundary layer (the spatial resolution of the thermography technique was insufficient to resolve a high gradient heating peak at this location), followed by a broad heating plateau $(0.02<\mathrm{x} / \mathrm{D}<0.1)$ interpreted as shear layer reattachment. As indicated by Gnoffo (2001), the original grid used in this numerical simulation was adapted from a mesh utilized for early flight predictions. This modified grid had finer resolution in the near wake relative to that used for the flight cases but no attempt was made to align the grid with the shear layer. Some degree of numerical diffusion of the shear layer was expected. The numerical heating spike at $\mathrm{x} / \mathrm{D}=0.24$ is grid induced (see Gnoffo, 1992 for details).

In an attempt to assess the sensitivity of wake closure characteristics and shear layer diffusion to grid alignment, a second calculation was made with the mesh realigned with wake streamlines. As anticipated, the realigned grid reduces the level of numerical shear layer diffusion and produces a sharper heating spike $\left(\mathrm{h} / \mathrm{h}_{\text {ref }}=0.33\right)$ at impingement. The location of this heating maximum $(\mathrm{x} / \mathrm{D}=0.12)$ occurs closer to the aerobrake base and further away from the experimental peak.

The rapid expansion of the flow around the MSRO shoulder and subsequent reattachment on the afterbody produces low wake densities with strong gradients. If these density gradients occur over distances that are small compared to the local flow mean free path, flowfield computations with Navier Stokes methods may incur inaccuracies. When this situation occurs, the continuum assumptions on which the Navier Stokes equations are based break down. Such flows typically have significant velocity slip along wall boundaries and a high degree of non-equilibrium between the translational modes as well as the internal degrees of freedom. These effects can produce significant errors in the Navier-Stokes modeling of viscous transport properties that are particularly important to the numerical calculations of the wake shear layer and reattachment shock. Bird (1994) proposed a continuum breakdown parameter that is essentially a Knudsen number with the length scale based on the local density gradient along streamlines. It has been suggested by Bird that for flow expansions, the initial breakdown of the continuum flow assumption correlates with a value near 0.02 or higher. Figure 25 shows the afterbody flow region of the MSRO for the laminar $\left(\mathrm{CF}_{4}\right)$ wind tunnel condition with regions of the flow shaded where the Bird breakdown parameter exceeds 0.02. This figure clearly shows significant regions of non-continuum flow downstream of the flow separation at the MSRO shoulder and in the reattachment shock region on the afterbody. The presence of these regions suggest that the Navier-Stokes predictions at this wind-tunnel condition may encounter errors in the numerical calculation of the wake shear layer development and impingement due to non-continuum effects. Presently, a 3-D coupled CFD-DSMC solution method has been implemented in an attempt to resolve differences between heating measurement and prediction (see Fig. 24) for this laminar test case. A Navier-Stokes simulation with the application of a velocity slip boundary condition at the wall near flow separation could also prove beneficial.

At the higher Reynolds numbers where rarefied-flow issues are not present, Navier Stokes computations with the support hardware included in the simulation would reduce the uncertainty posed by potential support interference. In addition, comparison of the turbulent $\mathrm{M}_{\infty}=6$ air data to numerical prediction using a two equation turbulence model are being considered.

\section{CONCLUSIONS}

The Langley 20-Inch Mach 6 Air and $\mathrm{CF}_{4}$ Tunnels were used to assess the afterbody heating characteristics of a proposed Mars Sample Return Orbiter (MSRO). The Mach $6 \mathrm{CF}_{4}$ tunnel utilizes a heavy gas (tetrafluoromethane$\mathrm{CF}_{4}$ ) in order to generate a higher value of normal shock density ratio (than can be achieved in air tunnels) which is more appropriate to simulation of hypervelocity flight through planetary or earth atmospheres. The primary experimental objectives were to determine if shear layer impingement would occur on the orbiter afterbody at incidence angles appropriate to an aerocapture maneuver, and if present, determine the location and magnitude of the heating peak for comparison of CFD predictions to measurement. Global heat transfer mappings, surface streamline patterns, and shock shapes were obtained for post-normal shock Reynolds numbers (based on forebody diameter) ranging from 1,420 to 415,000 , angles of attack ranging from -5 to 10 degrees at 0,3 , and 6 degree sideslip, and normal-shock density ratios of 5 and 12 . 


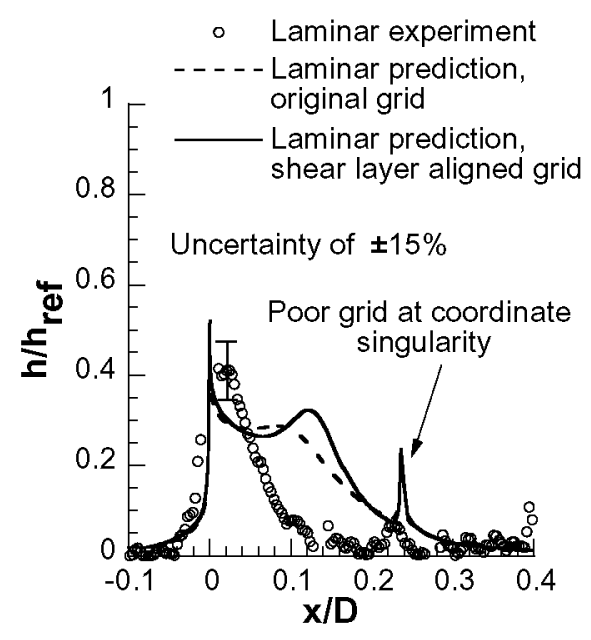

FIGURE 24. Comparison of Measured MSRO Laminar Impingement Zone Heating Distribution with Prediction. $\mathrm{M}_{\infty}=6, \mathrm{CF}_{4}, \mathrm{Re}_{2 \mathrm{D}}=3,946, \alpha=-4$ degrees.

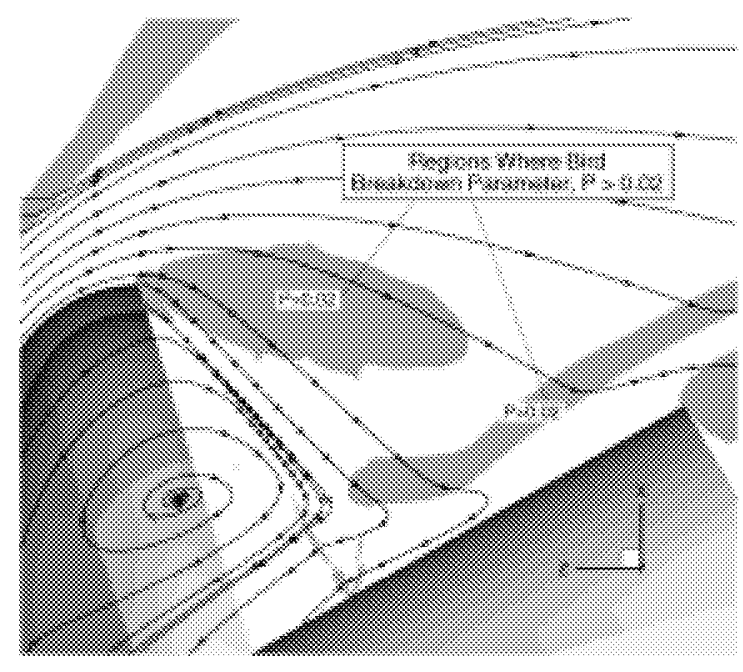

FIGURE 25. Continuum Breakdown Parameter (Bird, 1994) Based on Navier Stokes Predicted Near Wake Flowfield of the MSRO. $\mathrm{M}_{\infty}=6, \mathrm{CF}_{4}, \alpha=-4$ degrees.

The present MSRO laminar data is consistent with a previously developed correlation for blunt body wake shear layer turning and has suggested the general applicability of the correlation in providing initial design estimates defining the usable volume for payload placement behind an aerobrake. Based upon the present measurements, a non laminar wake shear layer (transitional or turbulent) is inferred for $\operatorname{Re}_{2 \mathrm{D}}>3,946$ and produces a larger shear layer turning angle (relative to a laminar counterpart). Laminar, transitional, and turbulent shear layer impingement on the cylindrical afterbody resulted in a localized heating maximum that ranged from 40 to 75 percent of the reference forebody stagnation point heating. In perspective, the post-normal shock Reynolds number for Mars entry at peak heating conditions is expected to be near $\mathrm{Re}_{2 \mathrm{D}}=83,000$. While the shear layer transition onset Reynolds number should not be applied directly to flight due primarily to the adverse effect of tunnel noise, the ground based measurements are considered conservative and suggest the possibility of a non-laminar wake during the aerocapture maneuver (particularly if transition initiated via forebody surface ablation or roughness).

Reynolds number and MSRO baseplane geometry (open and closed) have a pronounced effect on the magnitude of the nondimensional peak heating associated with shear layer impingement on the MSRO afterbody. For a laminar wake condition $\left(\operatorname{Re}_{2 \mathrm{D}}<3,946\right)$ in $\mathrm{M}_{\infty}=6 \mathrm{CF}_{4}$ at $\alpha=-4$ degrees, the peak heating associated with the closed baseplane is approximately $60 \%$ lower relative to that obtained with the open base (from $\mathrm{h} / \mathrm{h}_{\mathrm{ref}}=0.43$ to 0.27 ). For both base geometries, a non laminar base flow $\left(\operatorname{Re}_{2 \mathrm{D}}>3,946\right)$ produces a linear increase in reattachment heating with the log of the post shock Reynolds number based on body diameter. Curve fits to the data plotted in semilog form indicate the rate change of normalized peak heating associated with the closed base is approximately twice that of the open base. Thus, in contrast to the laminar situation, a turbulent wake in $M_{\infty}=6$ air $\left(\operatorname{Re}_{2 \mathrm{D}}=415,000\right)$ produces afterbody peak heating associated with the closed baseplane that is approximately $23 \%$ higher than that measured with the open base (from $\mathrm{h} / \mathrm{h}_{\mathrm{ref}}=0.73$ to 0.90 ). The turbulent wake associated with the closed MSRO base represents a worst case scenario in terms of afterbody heating where localized values at reattachment approached forebody stagnation levels.

Predicted values of a continuum breakdown parameter revealed significant regions of non-continuum flow downstream of the flow separation at the MSRO shoulder and in the reattachment shock region for the afterbody. The presence of these regions suggest that the Navier-Stokes predictions at the laminar wind-tunnel condition may encounter inaccuracies in the numerical prediction of the wake flowfield and surface properties due to non-continuum effects. 


\section{NOMENCLATURE}

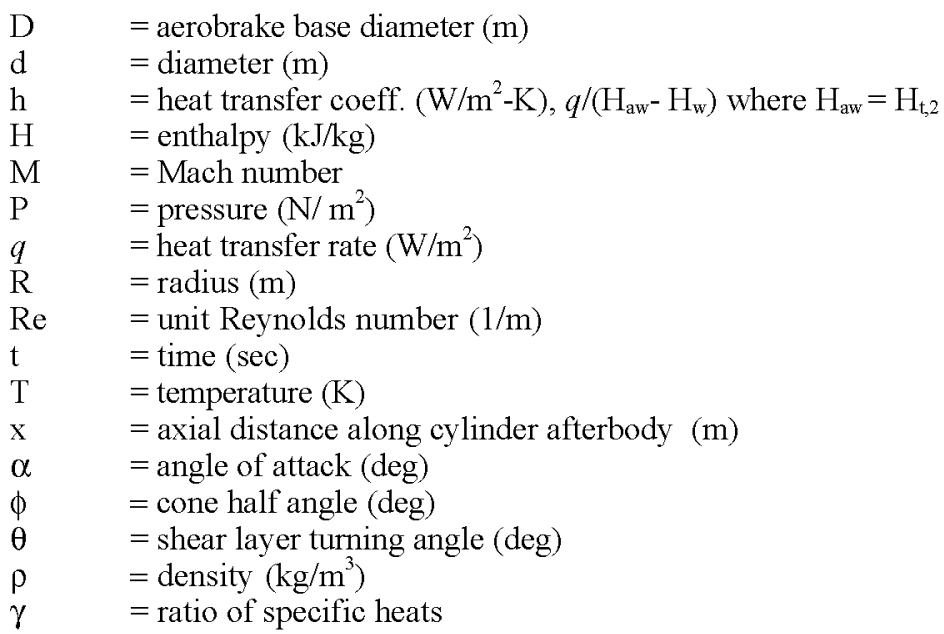

\section{Subscripts}

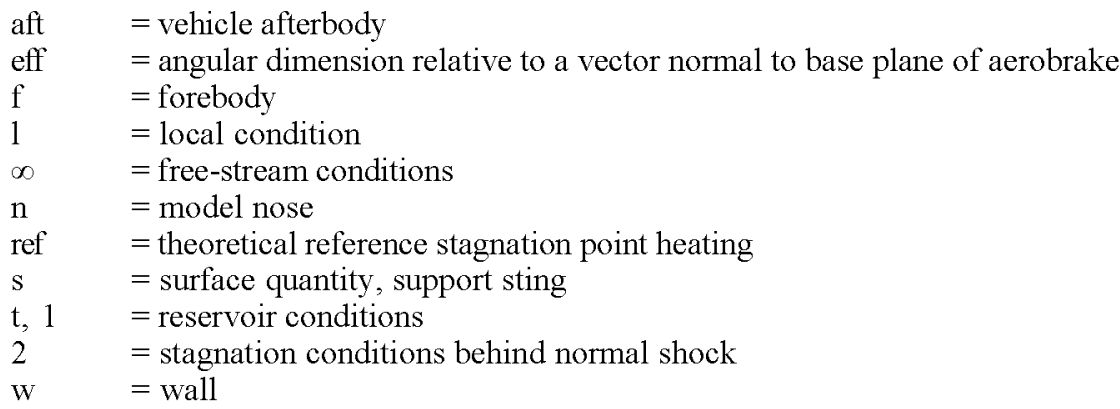

\section{ACKNOWLEDGMENTS}

Without the assistance of the following individuals, this work would not have been possible: Mark Cagle, Chris Glass, Joe Powers, Mike Powers, Mark Griffith, Steve Nevins, Gary Waynewright, and Ed Covington for model design, fabrication, and instrumentation; Melanie Lawhorne, Harry Stotler, Crystal Kellam, Al Garner, John Ellis, Grace Gleason, Rowland Hatten, and Steve Jones for wind tunnel support; Sheila Wright, Bert Senter and Mike Difulvio for data acquisition assistance; Scott Berry and Brian Hollis for analysis support; Peter Gnoffo for CFD analysis support; and Richard Wheless for documentation assistance. The authors gratefully acknowledge their contributions and behind-the- scenes work.

\section{REFERENCES}

Amundsen, R. M., Dec, J. A., Mitcheltree, R. A., Lindell, M. C., and Dillman, R. A., "Preliminary Thermal Analysis of a Mars Sample Return Earth Entry Vehicle," AIAA-2000-2584, June, 2000.

Baker, P. J. and Martin, B.W., "Heat Tranfer in Supersonic Separated Flow Over a Two-Dimensional Backward Facing Step," International Journal of Heat and Mass Transfer, 9 (1966).

Berger, S. A., Laminar Wakes, American Elsevier Publisher., Inc., 1971.

Berry, S. A., Bouslog, S. A., Brauckmann, G. J. and Caram, J. M., "Shuttle Orbiter Experimental Boundary-Layer Transition Results with Isolated Roughness," Journal of Spacecraft and Rockets, 35, No. 3, pp. 241-248 (1998a).

Berry, S. A., Horvath, T. J., DiFulvio, M., Glass, C. and Merski, N. R., "X-34 Experimental Aeroheating at Mach 6 and 10," Journal of Spacecraft and Rockets, 36, No. 2, pp. 171-178 (1998b).

Bird, G. A., Molecular Gas Dynamics and the Direct Simulation of Gas Flows, Oxford, Clarendon Press, 1994, p.4. 
Brauckmann. G. J., Paulson, J. W. and Weilmuenster, J. K., "Experimental and Computational Analysis of the Space Shuttle Orbiter Hypersonic Pitch-Up Anomaly," AIAA Paper 94-0632, January 1994.

Buck, G. M. and Vasquez, P., "An Investment Ceramic Slip-Casting Technique for Net-Form, Precision, Detailed Casting of Ceramic Models," U. S. Patent 5,266,252, November 30, 1993.

Buck, G. M., "Automated Thermal Mapping Techniques Using Chromatic Image Analysis," NASA TM 101554, April 1989.

Chanetz, B., "Study of the Mars Sample Return Orbiter in the Hypersonic Wind Tunnel R5Ch," Atmospheric Reentry Vehicles and Systems, Arcachon, France, March, 2001.

Cheatwood, F. M. and Gnoffo, P. A., "User's Manual for the Langley Aerothermodynamic Upwind Relaxation Algorithm (LAURA)," NASA TM 4674, April, 1996.

Cheatwood, F. M., DeJarnette, F. R. and Hamilton, H. H. II, "Geometrical Description for a Proposed Aeroassist Flight Experiment Vehicle," NASA TM-87714, July, 1986.

Dogra, V. K., Moss, J. N., Wilmoth, R. G., Taylor, J. C. and Hassan, H. A., "Effects of Chemistry on Blunt-Body Wake Structure," AIAA Journal, 33, No. 3, pp. 463-469 (1995).

Fay, J. A. and Riddell, F. R., "Theory of Stagnation Point Heat Transfer in Dissociated Air," Journal of Spacecraft and Rockets, 25, No. 2 (1958).

Gamble, J. D., "JSC Pre-Phase-A Study Mars Rover Sample Return Mission Aerocapture, Entry, and Landing Element," JSC23230, May, 1989.

Giraud, S. P., "Investigation of the MSRO Heat Flux Distribution at the VKI Longshot Facility" MARS-TN-MSRO-001-VKI, Feb., 2001.

Glass, C. E. and Gnoffo, P. A., "A 3-D Coupled CFD-DSMC Solution Method With Application To the Mars Sample Return Orbiter," in 22nd International Sym. On Rarified Gas Dynamics, paper 4003, July, 2000.

Gnoffo, P. A., Price, J. M. and Braun, R. D., "Computation of Near-Wake Aerobrake Flowfields," Journal of Spacecraft and Rockets, 29, No. 2, March-April, (1992)

Gnoffo, P. A., "An Upwind-Biased, Point-Implicit Relaxation Algorithm for Viscous Compressible Perfect Gas Flows," NASA TP 2953, Feb., 1990.

Gnoffo, P. A., "Computational Aerothermodynamics in Aeroasist Applications," AIAA Paper 2001-2632, June, 2001.

Gnoffo, P. A., "Planetary-Entry Gas Dynamics," Annual Review of Fluid Mechanics, pp.459-494 (1999)

Hollis, B. R., "Experimental and Computational Aerothermodynamics of a Mars Entry Vehicle," NASA CR 201633, Dec., 1996.

Horvath, T. J. and Hannemann, K., "Blunt Body Near Wake Flow Field at Mach 10," AIAA Paper 97-0986, Jan. 6-9, 1997.

Horvath, T. J., Berry, S. A., Hollis, B.R., Liechty, D.S. and Merski, N. R., "X-33 Experimental Aeroheating at Mach 6 Using Phosphor Thermography," AIAA Paper 99-3558, June, 1999.

Horvath, T. J., Berry, S. A., Merski, N. R. and Fitzgerald, S.M., "X-38 Experimental Aerothermodynamics," AIAA Paper 20002685 , June 2000 .

Horvath, T. J., McGinley, C. B. and Hannemann, K., "Blunt Body Near Wake Flow Field at Mach 6," AIAA Paper 96-1935, June, 1996.

Jones, R. A. and Hunt, J. L., "Use of Tetrafluoromethane to Simulate Real-Gas Effects on the Hypersonic Aerodynamics of Blunt Bodies," NASA TR R-312, 1974.

Merski, N. R., "Global Aeroheating Wind-Tunnel Measurements Using Improved Two-Color Phosphor Thermography Method" Journal of Spacecraft and Rockets, 36, No. 2, pp. 160-170 (1998a)

Merski, N. R., "Reduction and Analysis of Phosphor Thermography Data With the IHEAT Software Package," AIAA Paper 98-0712, Jan. 1998b.

Meyerson, R. E. and Cerimele, C. J., "Aeroassist Vehicle Requirements for a Mars Rover/Sample Return Mission," AIAA Paper 88-0303, Jan., 1988.

Midden, R. E. and Miller, C. G. III, "Description and Calibration of the Langley Hypersonic CF4 Tunnel, A Facility for Simulating Low Gamma Flow as Occurs for a Real Gas," NASA TP 2384, Oct., 1985.

Miller, C. G., "Langley Hypersonic Aerodynamic/Aerothermodynamic Testing Capabilities - Present and Future," AIAA Paper 90-1376, June 1990.

Mitcheltree, R. A., Kellas, S., Dorsey, J. T., Desai, P. N. and Martin, C.J., "A Passive Earth-Entry Capsule for Mars Sample Return," AIAA Paper 98-2851, June, 1998.

Nance, R.P. and Horvath, T. J., "Transition and Turbulence Modeling for Blunt-Body Wake Flows," AIAA Paper 97-2570, June 1997.

Pieri, D., "Rebuilding the U.S. Mars Exploration Program," Launchspace, July/Aug., 2000, p. 27.

Smith, B. A., "Lander Development Paced By Mars Science Results," Aviation Week \& Space Technology, June. 26, 2000a, p. 63.

Smith, B. A., "NASA Weighs Mission Options," Aviation Week \& Space Technology, Dec. 11, 2000b, p.54.

Taverna, M. A., "Europe to have Major Sample Return Role" Aviation Week \& Space Technology, Dec. 11, 2000, p.60

Wells, W. L., "Measured and Predicted Aerodynamic Heating on a Cylinder In Wake of AFE Configuration at Incidence," AIAA Paper 89-2162, 1989.

Williams, S.D., "A Preliminary TPS Design for MRSR-Aerobraking at Mars and at Earth," AIAA Paper 90-0052, Jan., 1990.

Wuerer, J. E. and Clayton, F. I., "Flow Separation in High-Speed Flight, A Review of the State-of-the-Art," Douglas Report SM-46429 April, 1965.

Zeiberg, S. L., "Transition Correlations for Hypersonic Wakes," AIAA Journal, 2, No. 3 (1964). 